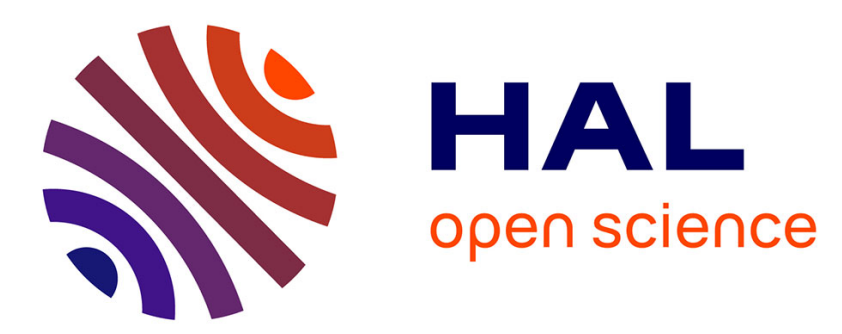

\title{
Controls of lithospheric structure and plate kinematics on rift architecture and evolution: An experimental modeling of the Baikal rift
}

\author{
G. Corti, E. Calignano, C. Petit, F. Sani
}

\section{- To cite this version:}

G. Corti, E. Calignano, C. Petit, F. Sani. Controls of lithospheric structure and plate kinematics on rift architecture and evolution: An experimental modeling of the Baikal rift. Tectonics, 2011, 30, pp.TC3011. 10.1029/2011TC002871 . hal-00620553

\section{HAL Id: hal-00620553 \\ https://hal.science/hal-00620553}

Submitted on 25 Oct 2021

HAL is a multi-disciplinary open access archive for the deposit and dissemination of scientific research documents, whether they are published or not. The documents may come from teaching and research institutions in France or abroad, or from public or private research centers.
L'archive ouverte pluridisciplinaire HAL, est destinée au dépôt et à la diffusion de documents scientifiques de niveau recherche, publiés ou non, émanant des établissements d'enseignement et de recherche français ou étrangers, des laboratoires publics ou privés.

\section{(c)(1)}

Distributed under a Creative Commons Attribution| 4.0 International License 


\section{Controls of lithospheric structure and plate kinematics on rift architecture and evolution: An experimental modeling of the Baikal rift}

Giacomo Corti, ${ }^{1}$ Elisa Calignano, ${ }^{2}$ Carole Petit, ${ }^{3,4}$ and Federico Sani ${ }^{2}$
Received 18 January 2011; revised 18 March 2011; accepted 31 March 2011; published 28 June 2011.

[1] Analog models investigate the evolution and architecture of the Baikal rift in relation to the rheology of the extending lithosphere and rift kinematics. The models focus on the development of the narrow, deep, and asymmetric basins composing Lake Baikal and reproduce the extension between the strong Siberian craton and the weaker Sayan-Baikal belt. Model results suggest that the presence of a near-vertical weak suture separating the cratonic keel from the mobile belt represents the more convenient rheological configuration leading to a narrow rift characterized by prominent vertical motions and deep depressions. These depressions are typically asymmetric, and model results suggest that this asymmetry is a consequence of lateral variations in lithospheric rheology, which is in turn related to both the variation in thickness of the strong mantle and, more importantly, the variation in the brittle-ductile transition depth between the craton and the belt. A significant shallowing of the brittle-ductile transition in the crust passing from the craton to the belt is required to fit the asymmetric architecture of the Baikal basins, with a master fault on the craton side and a monocline with no significant faulting on the belt side. Analysis of the model deformation pattern suggests that the overall architecture of the basins hosting Lake Baikal is best fitted for a $\mathrm{N} 140^{\circ} \mathrm{E}$ directed extension, similar to the current GPS-derived motion and compatible with the stress field inferred on the basis of fault and focal mechanism data. This kinematics (along with the shape of the Siberian craton) exerted the major control on the plan view fault architecture and its along-axis variations.

Citation: Corti, G., E. Calignano, C. Petit, and F. Sani (2011), Controls of lithospheric structure and plate kinematics on rift architecture and evolution: An experimental modeling of the Baikal rift, Tectonics, 30, TC3011, doi:10.1029/2011TC002871.

\section{Introduction}

[2] The deformation pattern resulting from continental rifting often exhibits a large degree of variability in terms of characteristics such as width, (a)symmetry, subsidence, architecture of faulting, etc., which may also vary in short distances along strike of a single rift [e.g., Ziegler and Cloetingh, 2004]. Among other controlling parameters, the variability in deformation pattern is likely to result from the inherited thermal and mechanical structure of the continental lithosphere at the time of rift inception: several previous works have indeed highlighted the localization of continental rifts along weak areas surrounding strong cratonic keels [e.g., Dunbar and Sawyer, 1989; Versfelt and Rosendahl, 1989;

\footnotetext{
${ }^{1}$ Consiglio Nazionale delle Ricerche, Istituto di Geoscienze e Georisorse, Florence, Italy.

${ }^{2}$ Dipartimento di Scienze della Terra, Università degli Studi di Firenze, Florence, Italy.

${ }^{3}$ ISTEP, Université Paris 6, Paris, France.

${ }^{4}$ Now at Geoazur, UMR 6526, CNRS-UNS-UPMC-IRD, Villefranchesur-mer, France.

Copyright 2011 by the American Geophysical Union. 0278-7407/11/2011TC002871
}

Tommasi and Vauchez, 2001; Chemenda et al., 2002; Corti et al., 2003; Ziegler and Cloetingh, 2004; Corti, 2009]. In these conditions, the juxtaposition between an old, cold and resistant lithosphere and a weaker domain, together with the geometry of the boundary between the different lithospheres in relation to the regional plate kinematics, is likely to influence the way how rifts develop and propagate, and at a more detailed scale, their architecture and symmetry [e.g., Ebinger et al., 1999]. Thus, horizontal variations in the rheology of the lithosphere, and not only its vertical layering [e.g., Buck, 1991], likely play a major role in controlling the distribution and architecture of the extensional deformation.

[3] The Baikal rift system is a long-lived ( $\sim 30 \mathrm{Ma})$ area of continental extension that extends for $\sim 1500 \mathrm{~km}$ in a NESW direction between the Eurasian and Amurian continental plates (Figure 1) [e.g., Logatchev and Florensov, 1978]. The rift is composed of several Late Cenozoic sedimentary basins displaying a large amount of asymmetry and important along-strike variations: whereas narrow, elongated, deep basins bounded by a single, southeastward dipping normal fault characterize the central and southwestern portions of the system [e.g., Hutchinson et al., 1992; van der Beek, 1997], the northernmost basins are shorter and spread over a larger area (though still largely asymmetric [e.g., Logatchev and 
Florensov, 1978]). The basins in the center-southwest of the rift host Lake Baikal, the deepest (maximum water depth of $\sim 1620 \mathrm{~m}$, reached in its central part) and most voluminous $\left(\sim 23.000 \mathrm{~km}^{3}\right)$ lake in the world that extends for $\sim 660 \mathrm{~km}$ with a mean width of $\sim 50 \mathrm{~km}$; these basins are also characterized by a thick sedimentary sequence, reaching in places a thickness of $\sim 9 \mathrm{~km}$ (Figure 1; see section 2). These deepest, narrowest depressions developed at the southern termination of the Archaean Siberian craton, in correspondence to a major lithospheric suture bounding and separating it from the Palaeozoic Sayan-Baikal fold belt; conversely, the more distributed, en echelon northernmost basins developed farther from this suture, within the mobile belt (Figure 1),
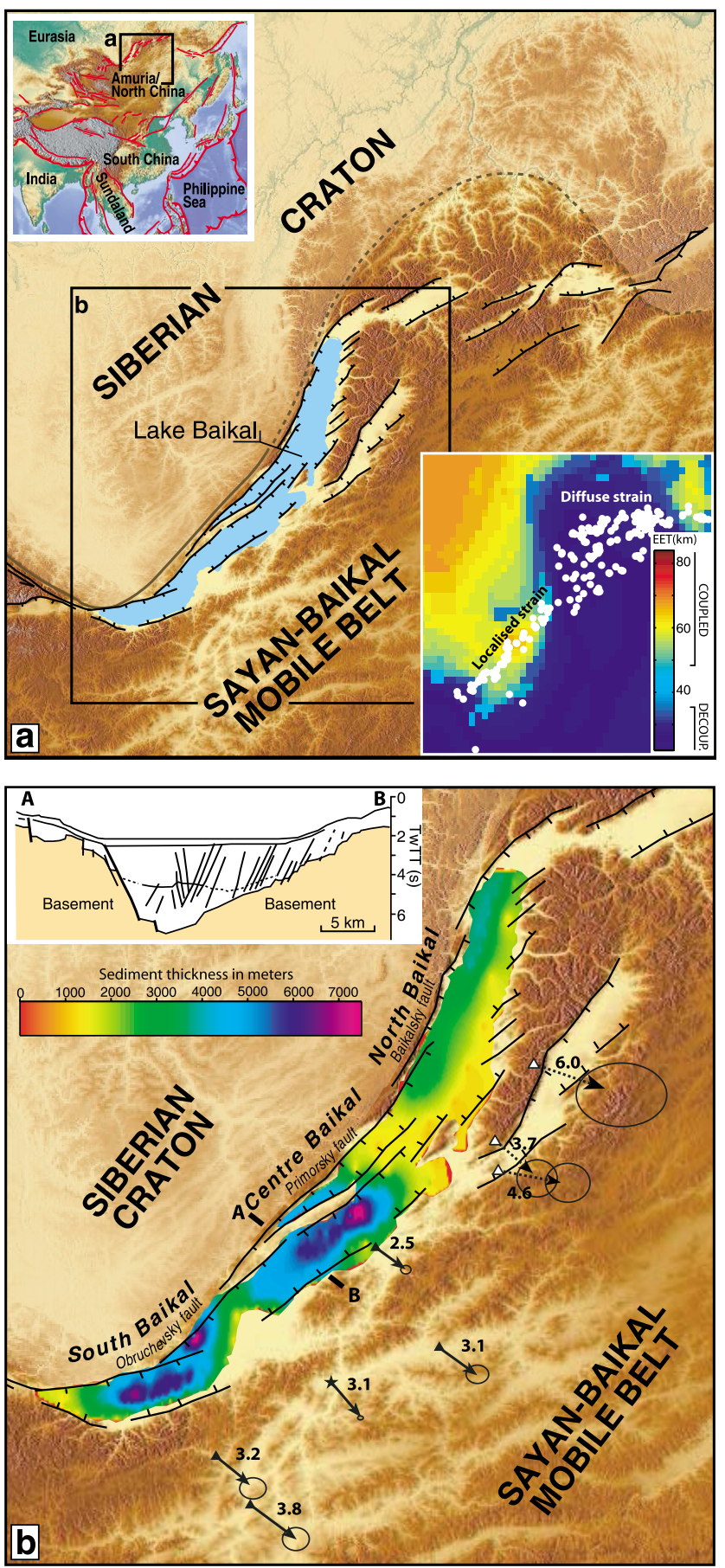

which suggests a rheological control on the distribution and architecture of extensional deformation between these two different domains [e.g., Chemenda et al., 2002; Petit et al., 2008]. In particular, rifting within a strong lithosphere at cratonic margins seems to be able to strongly localize deformation, which may result in the development of narrow, deep basins as also observed in Lake Tanganyika, at the western margin of the strong Tanzanian craton [e.g., Petit and Ebinger, 2000]. The juxtaposition between an old, cold and resistant lithosphere and a weaker domain is thus likely to influence the way how rifts develop and propagate [e.g., Chemenda et al., 2002], and at a more detailed scale, their architecture and symmetry.

[4] In this paper analog models are used to investigate the development of the Baikal rift, and to analyze the influence of the rheology of the extending lithospheres and rift kinematics on its architecture. The focus is on the development of the narrow, deep basins composing Lake Baikal; their analysis offers important insights into the development of narrow rifts at the margins of cratonic areas and involve general implications for some important aspects of continental rifting, such as the large degree of asymmetry often exhibited by continental rifts and passive margins worldwide [e.g., Ziegler and Cloetingh, 2004].

\section{Tectonic Setting}

[5] The Baikal rift system is composed of different Late Cenozoic sedimentary basins that follow an overall S-shaped curve from northern Mongolia to Eastern Siberia (Figure 1). The rift system is located against, or not far from, a major lithospheric suture bounding the southern termination of the

Figure 1. Structural setting of the Baikal rift system. (a) Topography and main tectonic features of the basins composing the Baikal rift system. Also shown is the hypothesized extent of the Siberian craton [after Petit et al., 2008]. Inset in the top left shows the location of the Baikal rift in Asia. Inset in the bottom right shows the effective elastic thickness of the lithosphere as predicted from thermorheological model [after Petit et al., 2008]. Values of effective elastic thickness higher than $\sim 50 \mathrm{~km}$ correspond to a coupled lithospheric rheology, whereas lower values correspond to a decoupled rheology. Distribution of earthquake epicenters, indicated as white dots, show a localized deformation in the Lake Baikal basin and a more distributed strain northeast of this basin. (b) Close-up of the fault pattern and topography of the Lake Baikal basins. The colored pattern indicates sediment thickness [after Petit and Déverchère, 2006]; note that depocenters (corresponding to sediment thickness up to $>7 \mathrm{~km}$ ) are located in the southwestern part of the basin. Black arrows indicate the present-day (1994-2007) GPS-derived velocity vectors relative to the Siberian Platform, shown with ellipses of a $95 \%$ confidence interval [after San'kov et al., 2009]. Symbols as follows: stars, stations of permanent measurements; solid triangles, field stations for long-term measurements; open triangles and dashed lines, field stations for measurements lasting 4 or fewer years. Numbers indicate motion velocities

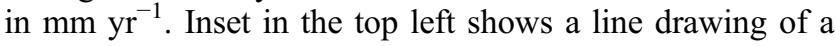
seismic section through the Centre Baikal (redrawn after van der Beek [1997]), illustrating the strong rift asymmetry with the major boundary fault located on the craton side. 
Siberian craton and separating it from the Sayan-Baikal fold belt (Figure 1). The latter is the result of several stages of continental accretion against the border of the craton which started in the Proterozoic and ended in the Late Jurassic [Delvaux et al., 1995; Melnikov et al., 1994; Zorin, 1999]. The prerift tectonic episodes have given the Sayan-Baikal belt a NE-SW inherited tectonic fabric which is still visible in the topography [e.g., Petit and Déverchère, 2006].

[6] The deepest and presumably oldest (i.e., Oligocene) rift basins localize on map against the suture in the southern and central rift zones (Figure 1). There, three narrow basins (South, Centre, and North Baikal) located in the southwestern half of the rift system host Lake Baikal; these basins, separated by two submerged structural highs, are largely asymmetric (Figure 1). The main boundary faults (e.g., Obruchevsky, Primorsky, and Baikalsky) are located on the northwestern margin; the opposite margin is characterized by a major monocline or by minor antithetic faults with subordinate vertical throw (Figure 1). Major bounding faults are long and linear in the South-Centre Baikal, whereas in the North Baikal the faults are generally shorter and en echelon arranged. The thickness of Cenozoic sediments reaches maximum values of $8-9 \mathrm{~km}$ in the South-Centre Baikal and decreases northward up to $\sim 4.5 \mathrm{~km}$ in the North Baikal (Figure 1) [Hutchinson et al., 1992; Petit and Déverchère, 2006]. To the northeast of Lake Baikal, the northern rift domain develops farther from the preexisting suture trace on map, within the Sayan-Baikal fold belt [de Boisgrollier et al., 2009]. Deformation in this area is distributed over a larger area characterized by the presence of shorter, still largely asymmetric en echelon basins developed within the Sayan-Baikal mobile belt [Logatchev and Florensov, 1978; Logatchev and Zorin, 1992].

[7] Present-day kinematics inferred from GPS data indicate that the southern and central parts of the rift are opening at a rate of about $3 \mathrm{~mm} \mathrm{yr}^{-1}$ in a NW-SE direction, i.e., almost orthogonal to the rift direction in this place [Calais et al., 2003; San'kov et al., 2009]. Whereas this kinematics seems to prevail since the Late Pliocene, geologic data indicate that the early stages of rift opening were likely dominated by a transtensional stress regime resulting in highly oblique rifting [Delvaux et al., 1997]. Estimates of the amount of total extension indicate low values of horizontal separation (likely $<20 \mathrm{~km}$ ) between the Eurasian and Amurian plates [Delvaux et al., 1997; San'kov et al., 2000; Zorin and Cordell, 1991; ten Brink and Taylor, 2002].

[8] Seismicity follows the distribution of active faults. Seismicity distribution at depth tends to indicate a resistant brittle crust down to depths of at least $30 \mathrm{~km}$, which was interpreted as the result of a cold, mafic lower crust [Déverchère et al., 2001]. Epicenters gather along a single belt delineating the South and Centre Baikal basins and split into several parallel belts and isolated seismic swarms in the north. Comparison between epicenters distribution and effective elastic thickness variations have led Petit et al. [2008] to propose that the southern and central parts of the rift develop in a thick and mechanically coupled lithosphere which could belong either to the craton or to a "strong" belt lithosphere, whereas the northern part locates within a weaker plate domain where crust and mantle are mechanically decoupled. This study is unable however to determine the 3-D geometry of the craton/mobile belt boundary. In addition, it provides only a present-day view of the strength variations of the lithosphere. Yet, the dip of the suture is interpreted to influence the along-axis variation in basin architecture and asymmetry: a northward decrease in suture dip is interpreted in another study to be responsible for an increase in rift symmetry and width [Petit and Déverchère, 2006]. In summary, several studies point out the role of an inherited mechanical heterogeneity (i.e., the juxtaposition of cratonic and "normal" lithospheres) in the rift development. However, the exact role of the suture in controlling rift development is still unknown: it is not clear if a mechanical weak zone is needed to strongly localize deformation or the rheological contrast between the craton and noncratonic lithosphere is sufficient to produce narrow, deep basins; also, it is not clear how the characteristics of the suture (e.g., dip) may influence rift architecture.

[9] Previous analog models of the Baikal rift [Chemenda et al., 2002] have confirmed the importance of a sharp lateral variation in rheology and the presence of a weak suture between the Siberian craton and the Sayan-Baikal belt in controlling rift development. These models, composed of single-layer elastoplastic lithosphere floating on a fluid asthenosphere, were able to reproduce the overall plan view geometry of the Baikal rift by introducing a weak zone (simulating the suture) that strongly localized deformation in the area of the natural Lake Baikal, and by accounting for the S-shaped geometry of the strong craton. However, this work did not investigate the complex architecture of the basins composing the rift (e.g., plan view fault pattern, basin asymmetry), nor the kinematics responsible for its development. Here we expand these previous results by analyzing in more detail the rifting process by means of centrifuge models characterized by a complex brittle-ductile continental lithosphere. We focus on the control of the lithospheric structure (and its lateral variation between the craton and the belt) and rift kinematics on the evolution and architecture (in terms of asymmetry, lateral variations in fault pattern, depocenters location, etc.) of the basins hosting Lake Baikal. The en echelon, NE-SW trending basins northeast of the lake, as well as the N-S depressions southwest of it are not considered in this work. We focus on Lake Baikal because rifting here is suggested to closely follow the suture at the border of the craton [e.g., Petit and Déverchère, 2006], whose geometry is reasonably constrained. This allows comparison with analog models with similar geometry and variable direction of extension in order to give insights into the presumed kinematics of deformation and rheological stratification responsible for basin architecture and evolution. Since the geometry of the craton beneath the en echelon basins northeast of Lake Baikal is less constrained, being the boundary between the different lithospheres masked beneath the Sayan-Baikal belt units and by large granitoid intrusives of the Angara-Vitim batholith, comparison of oblique/orthogonal rifting model results cannot be easily applied to the fault pattern of this region. For these reasons, these en echelon basins will not be discussed further.

\section{Model Setup and Experimental Series}

[10] The experimental setup was based on a well-established modeling approach in which experiments reproducing 

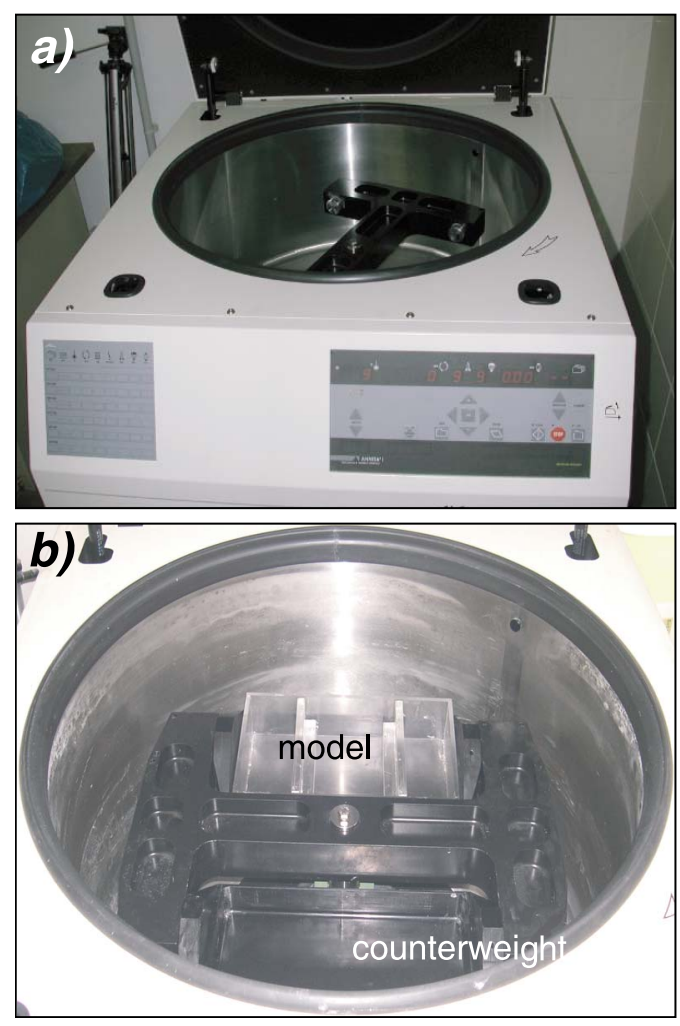
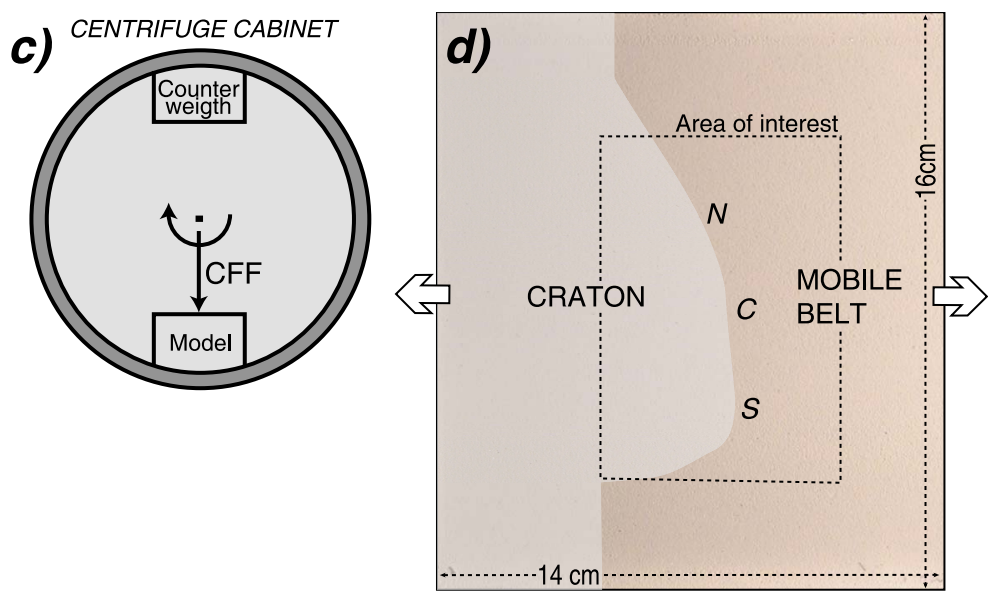

e)

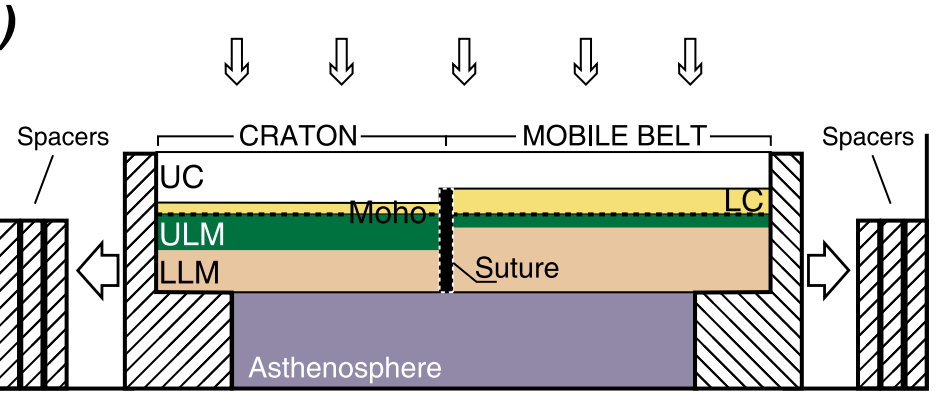

Figure 2. Experimental setup. (a) Frontal view of the large-capacity centrifuge, (b) close-up of the internal rotor and (c) loading conditions in the centrifuge (CFF, centrifuge force field). (d) Top-view photo of the models, illustrating the geometry of the craton and the weaker mobile belt. Letters $N, C$, and $S$ indicate the areas in the model corresponding the location of the North, Centre, and South sectors of the natural Baikal rift. (e) Model cross section illustrating the vertical rheological layering and schematic representation of the extension conditions during a centrifuge run (see text for details). LC, lower crust; LLC, lower lithospheric mantle; UC, upper crust; ULM, upper lithospheric mantle.

continental rifting are performed in an artificial gravity field of $\sim 18 \mathrm{~g}$ by using the large capacity centrifuge at the Tectonic Modeling Laboratory of the Institute of Geosciences and Earth Resources (National Research Council of Italy) at the Earth Sciences Department of the University of Florence. The experiments simulated extension of a brittleductile continental lithosphere floating above a low viscosity material representing the asthenosphere (Figure 2). The models were built inside a transparent rectangular Plexiglas box (with internal dimensions of $25 \times 16 \times 7 \mathrm{~cm}$ ) and confined by two moveable sidewalls; removal of rectangular blocks (spacers) at the sides of these moving walls allowed vertical thinning and lateral extension of the models in response to the centrifugal forces to fill the empty space (Figure 2). Sequential removal of spacers during successive runs in the centrifuge allowed controlling the amount and rate of extension [e.g., Corti et al., 2003]. Top-view photos and laser scans of the models were taken after the end of each centrifuge run. After a successful experiment, the models were frozen before taking a number of cross sections to study their 3-D internal geometry.

[11] The brittle-ductile model lithosphere was characterized by a lateral variation in rheological layering between a high-strength craton (representative of the strong Siberian shield) and a strong mobile belt (simulating the SayanBaikal belt); most of the model involved the presence of a weak suture zone between the two lithospheres (Figure 2), although different rheological configurations were tested in different experiments (see section 3.3). The application of a homogeneous stress field (imposed by the centrifugal body forces) to this laterally varying rheology allowed exploring the response of this heterogeneous continental lithosphere to extension, thus providing insights into the role of the variation in vertical rheological layering on the evolution and architecture of the Baikal rift.

\subsection{Rheological Layering and Experimental Materials}

[12] A vertical sequence of brittle and ductile materials was used to reproduce the rheological multilayering characteristic of the craton and mobile belt lithospheres (Figure 2). In both lithospheres, the materials used to reproduce the crustal and mantle layers were the same, although the thickness of these different layers was varied in order to reproduce variations in lithospheric strength. The rheology of these lithospheres (e.g., resistance and thickness) was simulated by reference to the vertical rheological layering and strength profiles illustrated by Petit et al. [2008]. The brittle upper crust was simulated by using a K-feldspar powder characterized by a linear increase in strength with depth well reproducing the natural brittle behavior. The lower crust was modeled with a ductile mixture of silicone (Wacker Silicone Bouncing Putty 29 distributed by CRC 
France, hereafter referred to as Wacker BP29) and corundum sand (100:20\% in weight). A mixture (100:45\% in weight) of plasticine (Pongo $\AA$ modeling dough, distributed by FILA) and PDMS (Polydimethylsiloxane; silicone SGM36 distributed by Dow Corning) was used to simulate the strong uppermost lithospheric mantle, whereas the lower lithospheric mantle was made of a Wacker BP29 corundum sand mixture (100:80\% in weight). A weak suture between the craton and the mobile belt was modeled with a Wacker BP29 corundum sand-oleic acid mixture (100:80:15\% in weight). The weak zone was placed in the lower crust and in the mantle, whereas in nature the suture likely extends through the whole lithosphere. Thus, our setup simplified the natural process where inherited fabrics characterize the brittle crust; however, model results suggest that these fabrics played a minor role in controlling the deformation pattern (see below).

[13] The crustal-mantle layers rested on a low viscosity mixture made of Wacker BP29 corundum sand-oleic acid mixture (100:100:20\% in weight). Details of these materials are summarized by Agostini et al. [2009] and their rheological characteristics illustrated in Figure S1; their use allows obtaining an increase in density with depth and a variable strength reproducing a typical Christmas tree strength profile of the continental lithosphere (Figure S1). ${ }^{1}$ In some experiments, syntectonic sedimentation was simulated by filling the rift depression (up to the top of the rift shoulders) with sieved $\mathrm{K}$-feldspar powder before running the model in the centrifuge.

\subsection{Scaling}

[14] In order to fit the large-scale, plan view geometry of the Baikal rift into the modeling Plexiglas box, the models were built with a geometric scale ratio of $1.3 \times 10^{-7}$, such that $1 \mathrm{~cm}$ in the experiments corresponded to $\sim 75 \mathrm{~km}$ in nature. This allowed modeling $\sim 20-25 \mathrm{~km}$ of total extension of $\sim 90-105 \mathrm{~km}$ thick continental lithospheres; in cross section, the thickness and relative strength of crustal and mantle layers was taken from the calculations reported by Petit et al. [2008]. Dynamic-kinematic similarity of gravitational, viscous and frictional stresses acting in the system [Ramberg, 1981] ensured that the velocity of extension in the models $\left(\sim 1-2 \times 10^{-5} \mathrm{~m} \mathrm{~s}^{-1}\right)$ scaled to natural values of

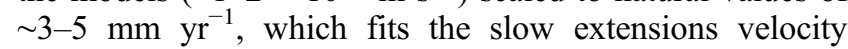
observed through GPS measurements [e.g., Calais et al., 2003; San'kov et al., 2009]. The scaled total resistance of the craton lithosphere (calculated according to the procedure outlined by Corti et al. [2004] and Agostini et al. [2009]) was $\sim 4 \times 10^{13} \mathrm{Nm}^{-1}$; the strength of the mobile belt was $\sim 40 \%$ that of the craton, and dropped to $\sim 10 \%$ in the weak suture (see Figure S1).

\subsection{Experimental Series}

[15] Two main experimental series were performed to analyze the geodynamics of the Baikal rift (Table 1). Experiments of Series 1 investigated the influence of the rheology of the extending continental lithospheres (craton and mobile belt) on rift architecture and evolution. Since the rift structure in the Baikal rift appears to be strongly controlled by the

\footnotetext{
${ }^{1}$ Auxiliary materials are available in the HTML. doi:10.1029/ 2011 TC002871.
}

presence and geometry of a weak suture zone bounding the Siberian craton [e.g., Petit and Déverchère, 2006], the majority of the models of this series involved the presence of a major weakness zone between the craton and the belt. However, models with no weak zone between the craton and the mobile belt were performed for comparison (subseries 1a). Moreover, numerical modeling by Petit et al. [2008] have shown that the overall rift architecture is mostly controlled by lateral variations in strength contrast between the craton and mobile belt and, in particular, by a variable crustmantle coupling, in turn controlled by variations in thickness of the ductile lower crust (acting as the decoupling layer) in the mobile belt. Most of the models investigated the influence of this parameter on rift architecture (subseries 1b), by considering a variable depth of the brittle-ductile crust transition (i.e., variations in the thickness ratio of the upper and lower crust) in the mobile belt, for a constant craton rheology and a flat Moho at both sides of the suture zone [see Petit et al., 2008]. In addition, experiments of Series 1 have analyzed the role of a variable suture dip on rift architecture (subseries 1c): this parameter has been indeed suggested to have a possible control on rift asymmetry and its variation along the axis of the Baikal rift [Petit and Déverchère, 2006]. Other parameters investigated (although less extensively) of Series 1 experiments include: the variation in thickness of the strong lithospheric mantle both in the belt and the craton (subseries 1d), the variation in thickness of the brittle crust (subseries 1e) the variation in the width of the weak suture (subseries 1f), the role of syntectonic accumulation of sediments during progressive subsidence of the rift zone (subseries 1g), and the presence of a thinner lower lithospheric mantle in the mobile belt (subseries $1 \mathrm{~h}$ ).

[16] Series 2 investigated the variation in rift kinematics on rift architecture. In this series, for a constant geometry of the craton and the weak suture at its border, different experiments analyzed the fault pattern and the main rift characteristics resulting from a variation in the stretching vector direction. In particular, this series includes three different experiments characterized by extension direction trending $\mathrm{E}-\mathrm{W}, \mathrm{N} 115^{\circ} \mathrm{E}$ and $\mathrm{N} 140^{\circ} \mathrm{E}$. The $\mathrm{E}-\mathrm{W}$ extension was selected since it has been suggested to have characterized the early stages of rift opening [Delvaux et al., 1997]; the $\mathrm{N} 140^{\circ} \mathrm{E}$ extension represents the present-day kinematics [Calais et al., 2003; San'kov et al., 2009] and likely controlled rift opening since the Late Pliocene [Delvaux et al., 1997]; the $\mathrm{N} 115^{\circ} \mathrm{E}$ directed extension was chosen to test an intermediate value of rift kinematics.

[17] In each experimental series or subseries, apart from the parameter under investigation the other boundary conditions were kept constant. In total 41 experiments were performed. The experiments were analyzed in terms of the main characteristics to be compared with the natural prototype (e.g., asymmetry, rift width, depocenter location, fault architecture, etc.); each experiment was repeated several times and, although the models may have differed in small details, the first-order evolution of deformation (e.g., fault architecture and evolution) was always comparable.

\section{Experimental Results}

[18] The typical evolution of the reference model (Baikal 14) is illustrated in Figure 3. This model had a weak suture 
Table 1. Characteristics of Selected Representative Models Discussed in the Text and/or Shown in Figures 3-10 and S2-S5

\begin{tabular}{|c|c|c|c|c|c|c|c|c|c|c|}
\hline \multirow[b]{2}{*}{ Model } & \multirow[b]{2}{*}{$\begin{array}{l}\text { Experimental } \\
\text { Series }\end{array}$} & \multicolumn{3}{|c|}{$\begin{array}{c}\text { Layer Thickness }{ }^{\mathrm{a}} \\
(\mathrm{mm})\end{array}$} & \multirow{2}{*}{$\begin{array}{c}\text { Step in } \\
\text { Brittle-Ductile } \\
\text { Transition Depth } \\
\text { (mm) }\end{array}$} & \multirow{2}{*}{$\begin{array}{l}\text { Suture } \\
\text { Width } \\
(\mathrm{mm})\end{array}$} & \multirow[b]{2}{*}{$\begin{array}{l}\text { Suture } \\
\text { Dip }\end{array}$} & \multirow[b]{2}{*}{$\begin{array}{l}\text { Direction of } \\
\text { Extension }\end{array}$} & \multirow[b]{2}{*}{$\begin{array}{c}\text { Synrift } \\
\text { Sedimentation }\end{array}$} & \multirow{2}{*}{$\begin{array}{l}\text { Amount of } \\
\text { Extension } \\
(\mathrm{mm})\end{array}$} \\
\hline & & Layer & Craton & Belt & & & & & & \\
\hline \multirow[t]{4}{*}{ Baikal 06} & $1 \mathrm{a}$ & UC & 5 & 5 & 0 & 0 & - & $\mathrm{N} 140^{\circ} \mathrm{E}$ & No & 5 \\
\hline & & $\mathrm{LC}$ & 1 & 1 & & & & & & \\
\hline & & ULM & 3 & 0 & & & & & & \\
\hline & & LLM & 4 & 7 & & & & & & \\
\hline \multirow[t]{4}{*}{ Baikal 10} & $1 \mathrm{~b}$ & $\mathrm{UC}$ & 5 & 3 & 2 & 1 & 90 & $\mathrm{~N} 140^{\circ} \mathrm{E}$ & No & 3.5 \\
\hline & & $\mathrm{LC}$ & 1 & 3 & & & & & & \\
\hline & & ULM & 3 & 1 & & & & & & \\
\hline & & LLM & 4 & 6 & & & & & & \\
\hline \multirow[t]{4}{*}{ Baikal 13} & $1 \mathrm{~h}$ & $\mathrm{UC}$ & 5 & 3 & 2 & 1 & 90 & $\mathrm{~N} 140^{\circ} \mathrm{E}$ & No & 3.5 \\
\hline & & $\mathrm{LC}$ & 1 & 3 & & & & & & \\
\hline & & ULM & 3 & 1 & & & & & & \\
\hline & & LLM & 4 & 2 & & & & & & \\
\hline \multirow{4}{*}{ Baikal 14} & Reference model & $\mathrm{UC}$ & 5 & 5 & 0 & 1 & 90 & $\mathrm{~N} 140^{\circ} \mathrm{E}$ & No & 3 \\
\hline & & $\mathrm{LC}$ & 1 & 1 & & & & & & \\
\hline & & ULM & 3 & 1 & & & & & & \\
\hline & & LLM & 4 & 6 & & & & & & \\
\hline \multirow[t]{4}{*}{ Baikal 15} & $1 b$ & $\mathrm{UC}$ & 5 & 4 & 1 & 1 & 90 & $\mathrm{~N} 140^{\circ} \mathrm{E}$ & No & 2.5 \\
\hline & & $\mathrm{LC}$ & 1 & 2 & & & & & & \\
\hline & & ULM & 3 & 1 & & & & & & \\
\hline & & LLM & 4 & 6 & & & & & & \\
\hline \multirow[t]{4}{*}{ Baikal 16} & $1 \mathrm{~b}$ & $\mathrm{UC}$ & 5 & 2 & 3 & 1 & 90 & $\mathrm{~N} 140^{\circ} \mathrm{E}$ & No & 3.5 \\
\hline & & $\mathrm{LC}$ & 1 & 4 & & & & & & \\
\hline & & ULM & 3 & 1 & & & & & & \\
\hline & & LLM & 4 & 6 & & & & & & \\
\hline Baikal 19 & $1 \mathrm{e}$ & $\mathrm{UC}$ & 10 & 8 & 2 & 1 & 90 & $\mathrm{~N} 140^{\circ} \mathrm{E}$ & No & 3 \\
\hline & & $\mathrm{LC}$ & 1 & 3 & & & & & & \\
\hline & & ULM & 3 & 1 & & & & & & \\
\hline & & LLM & 4 & 6 & & & & & & \\
\hline Baikal 24 & $1 \mathrm{f}$ & $\mathrm{UC}$ & 5 & 5 & 0 & 2 & 90 & $\mathrm{~N} 140^{\circ} \mathrm{E}$ & No & 3 \\
\hline & & $\mathrm{LC}$ & 1 & 1 & & & & & & \\
\hline & & ULM & 4 & 2 & & & & & & \\
\hline & & LLM & 4 & 6 & & & & & & \\
\hline Baikal 31 & $1 d$ & $\mathrm{UC}$ & 5 & 5 & 0 & 1 & 90 & $\mathrm{~N} 140^{\circ} \mathrm{E}$ & No & 3 \\
\hline & & $\mathrm{LC}$ & 1 & 1 & & & & & & \\
\hline & & ULM & 4 & 2 & & & & & & \\
\hline & & LLM & 4 & 6 & & & & & & \\
\hline Baikal 32 & $1 \mathrm{c}$ & $\mathrm{UC}$ & 5 & 5 & 0 & 1 & 45 & $\mathrm{~N} 140^{\circ} \mathrm{E}$ & No & 3.5 \\
\hline & & $\mathrm{LC}$ & 1 & 1 & & & & & & \\
\hline & & ULM & 4 & 2 & & & & & & \\
\hline & & LLM & 4 & 6 & & & & & & \\
\hline Baikal 33 & 2 & $\mathrm{UC}$ & 5 & 5 & 0 & 1 & 90 & $\mathrm{~N} 90^{\circ} \mathrm{E}$ & No & 3 \\
\hline & & $\mathrm{LC}$ & 1 & 1 & & & & & & \\
\hline & & ULM & 4 & 2 & & & & & & \\
\hline & & LLM & 4 & 6 & & & & & & \\
\hline Baikal 34 & 2 & $\mathrm{UC}$ & 5 & 5 & 0 & 1 & 90 & $\mathrm{~N} 115^{\circ} \mathrm{E}$ & No & 2 \\
\hline & & LC & 1 & 1 & & & & & & \\
\hline & & ULM & 4 & 4 & & & & & & \\
\hline & & LLM & 4 & 4 & & & & & & \\
\hline Baikal 38 & $1 \mathrm{~g}$ & UC & 5 & 3 & 2 & 1 & 90 & $\mathrm{~N} 140^{\circ} \mathrm{E}$ & Yes & 2.5 \\
\hline & & $\mathrm{LC}$ & 1 & 3 & & & & & & \\
\hline & & ULM & 3 & 1 & & & & & & \\
\hline & & LLM & 3 & 5 & & & & & & \\
\hline Baikal 41 & 1a & UC & 5 & 5 & 0 & 0 & - & $\mathrm{N} 140^{\circ} \mathrm{E}$ & No & 3.5 \\
\hline & & LC & 1 & 1 & & & & & & \\
\hline & & ULM & 3 & 1 & & & & & & \\
\hline & & LLM & 4 & 6 & & & & & & \\
\hline
\end{tabular}

${ }^{\mathrm{a}} \mathrm{UC}$, upper crust; LC, lower crust; ULM, upper lithospheric mantle; LLM, lower lithospheric mantle. In all the models, these layers overlie a $1 \mathrm{~cm}$ thick asthenosphere.

separating the craton from the mobile belt; as derived from Petit et al. [2008], both lithospheres had a strong upper lithospheric mantle, although thinner in the belt than in the craton. The thickness of the upper and lower crust was similar at both sides of the suture and the difference in strength between the craton and the mobile belt was only given by the different thickness of the strong upper lithospheric mantle.

[19] Model evolution shows the initial development of a major normal fault at the margin of the high-strength craton; this major fault formed in correspondence to the model South-Centre Baikal, i.e., where the craton border was 


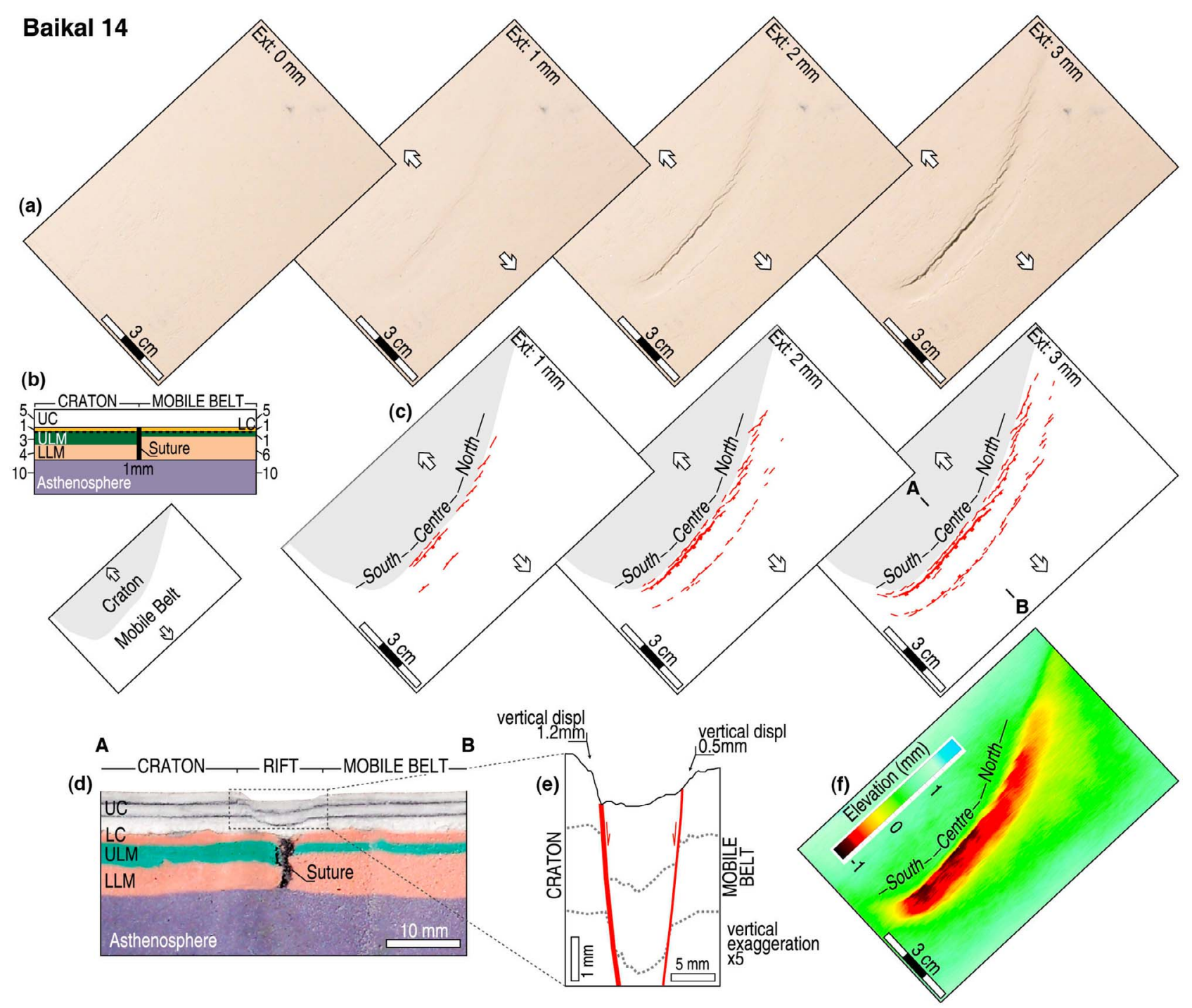

Figure 3. Evolution and characteristics of deformation of the reference model Baikal 14. (a) Sequential top-view photos of the model, illustrating the evolution of deformation for increasing extension. The model is rotated of $47^{\circ}$ clockwise to fit the trend and geometry of the natural Baikal rift. Ext: indicates the amount of extension. (b) Initial model setup and (c) line drawing of deformation for increasing extension. Note the long, linear major boundary fault system on the craton side in the model South-Centre Baikal and the en echelon arrangement of shorter normal faults in the model North Baikal. (d) Photo of model cross section, (e) with close-up illustrating the topographic profile of the central rift depression (vertical exaggeration $\times 5$ ) with a structural interpretation, and (f) digital elevation model of the model surface at the end of deformation. Note the rift asymmetry, with the presence of a major boundary fault on the craton side; also note the occurrence of the basin depocenters in the model South-Centre Baikal.

orthogonal to the direction of extension, and the fault itself was perpendicular to the stretching direction. After development of this major fault, minor faults formed in the model North Baikal, i.e., where the craton margin curved to become oblique to the stretching vector. An incipient rift valley was defined by subordinate antithetic faults on the border of mobile belt. Progressive extension led to both vertical and lateral growth of the major border fault; this fault was linear in plan view and characterized by the largest vertical throw of the whole fault set. Antithetic faults on the mobile belt border displayed about half of the vertical throw of the major border fault, defining an asymmetric rift valley whose trend closely followed the trend and geometry of the model craton. Leftstepping, en echelon, oblique slip faults characterized the model North Baikal; similarly, antithetic faults on the mobile belt side were oblique and en echelon arranged. These en echelon faults defined a narrower rift depression with respect to the model Centre-South Baikal, testifying a transition from pure extension in these latter areas to oblique rifting (i.e., a component of strike-slip deformation) where the craton was 


\section{Baikal 14 Suture}

(a)

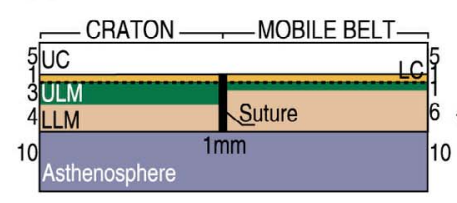

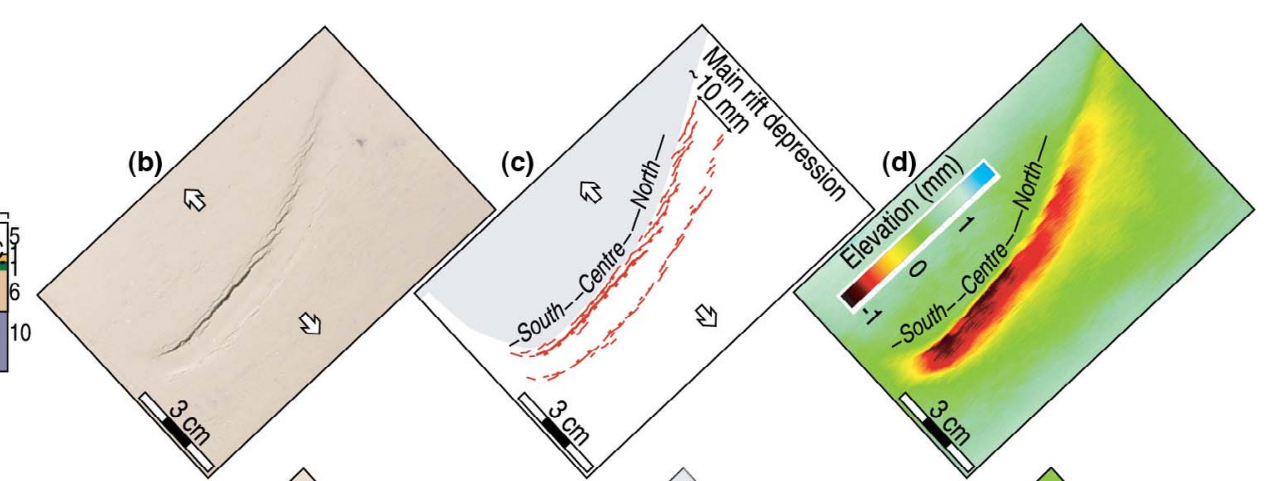

\section{Baikal 41 No Suture, strong ULM}

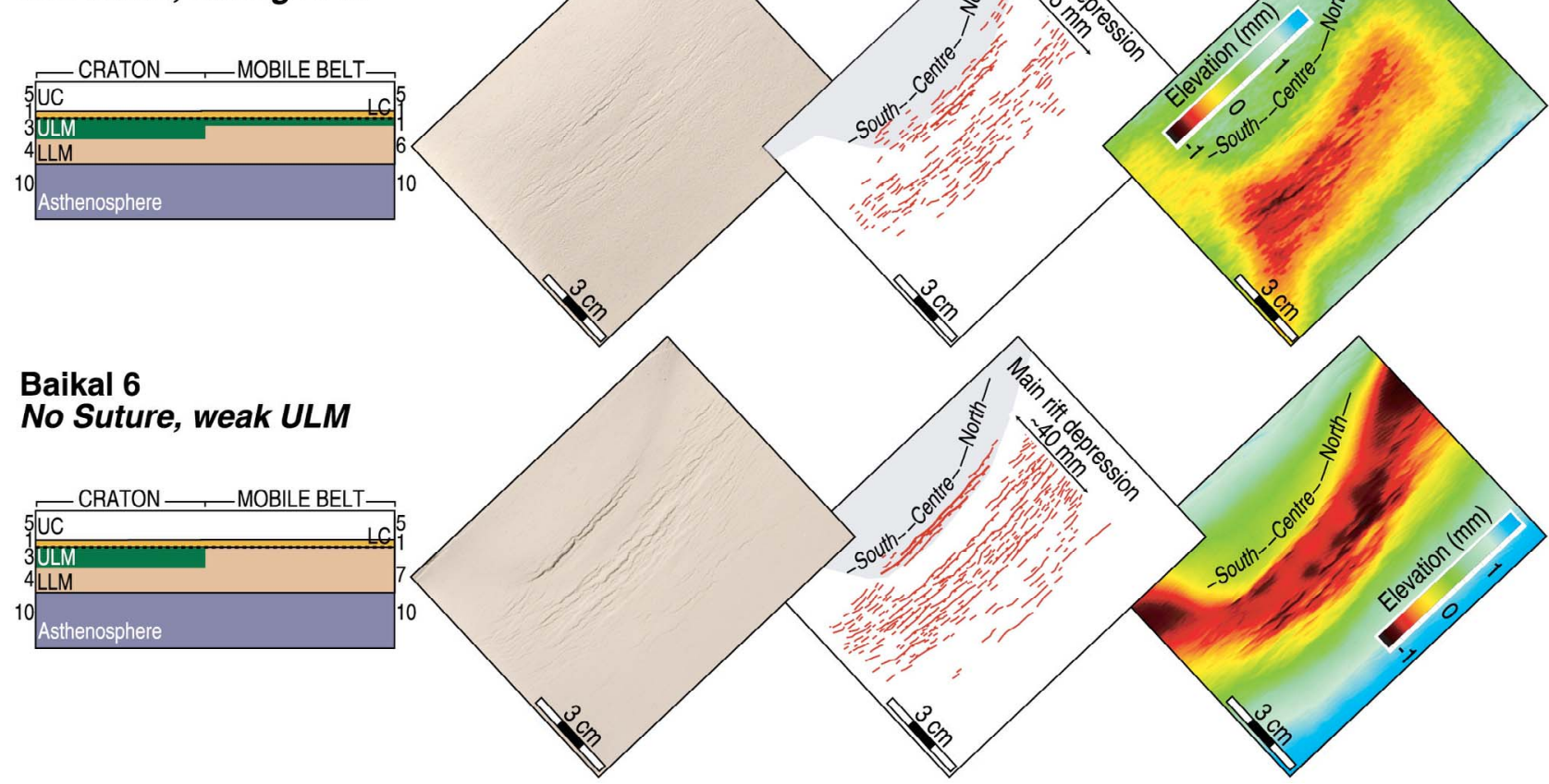

Figure 4. Comparison of the deformation pattern in models with or without a preexisting weak suture and different rheological configurations in the mobile belt, illustrated as (a) initial model setup, (b) topview photo, (c) line drawing of deformation, and (d) digital elevation model of the model surface. (top) Deformation of the reference model, with no preexisting suture; (middle) deformation of model Baikal 41, with no suture and strong upper lithospheric mantle; and (bottom) deformation of model Baikal 6, with no suture and weak mantle (absence of the strong lithospheric mantle). Note that a localized deformation (with scaled rift width comparable to the natural Baikal rift, i.e., $<80 \mathrm{~km}$ ) is only obtained in the presence of a preexisting suture separating the craton from the mobile belt. When the weak suture is absent, extension results in wide deformation zones (with scaled values on the order of 200-300 km), irrespective of mantle strength. Symbols are as in Figure 2.

oblique to extension. There, basin subsidence was less pronounced, in accord with the oblique extension conditions that promote a reduction in vertical motion and increase in horizontal component of motion (see also section 4.2).

[20] The final model cross section illustrated in Figure 3 showed strongly localized thinning of the model lithosphere in correspondence to the suture zone, where a minor asthenospheric upwelling was observed. The upper crust showed an asymmetric deformation, with the major boundary fault on the craton side accommodating $\sim 1.2 \mathrm{~mm}$ (scaled value $\sim 9 \mathrm{~km}$ ) of vertical displacement, whereas the antithetic faults accommodated less than half of this value. Analysis of the digital elevation model of the model surface confirmed an asymmetric subsidence of the basin. The basin depocenter was located on the craton border of the model South-Centre Baikal; subsidence typically decreased both toward the mobile belt and toward the model North Baikal.

\subsection{Results: Rheology}

[21] As illustrated above, the reference model (characterized by a weakness separating a craton lithosphere from a mobile belt with thin, strong upper lithospheric mantle) 


\section{Baikal 10}

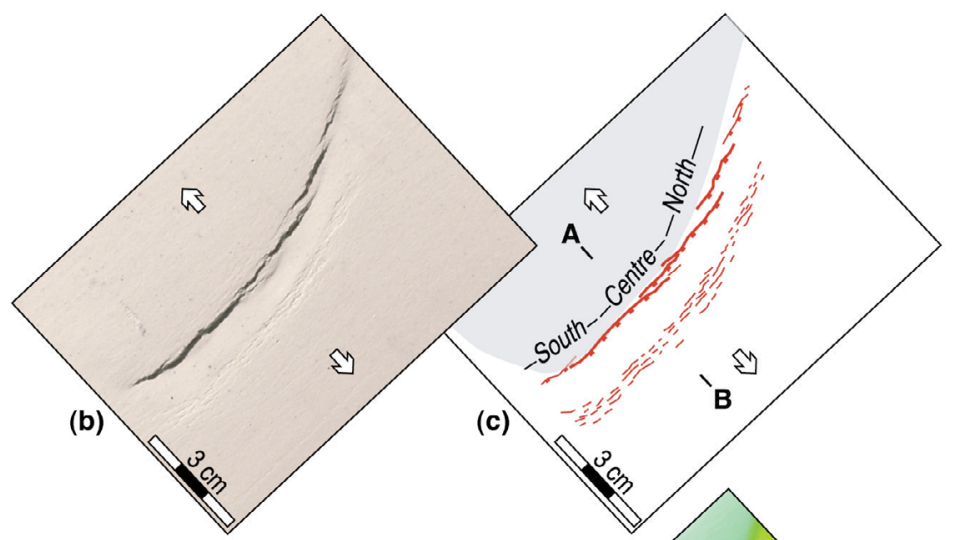

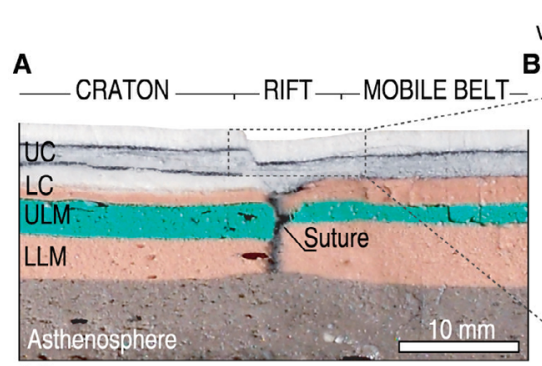

(d) (a)

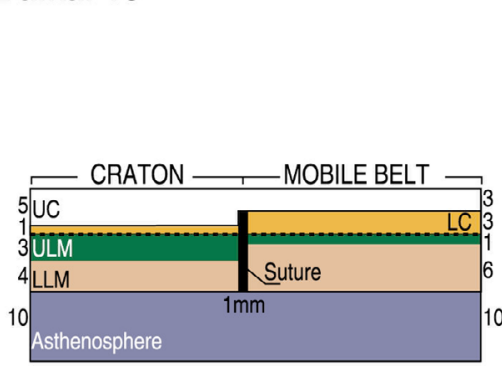

(b)

(c)

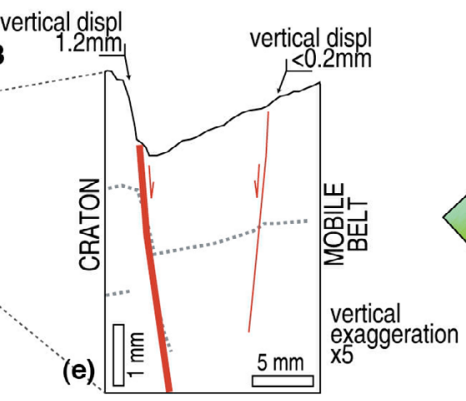


Baikal 14

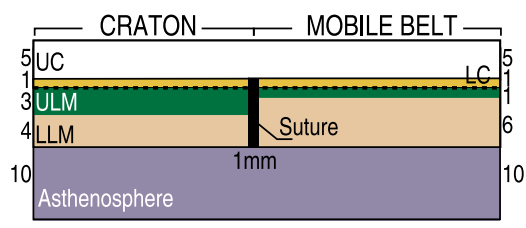

Baikal 15

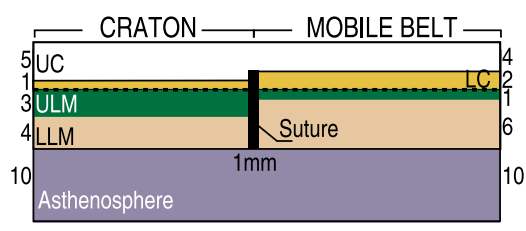

Baikal 10

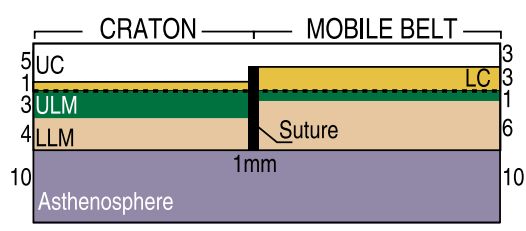

Baikal 16

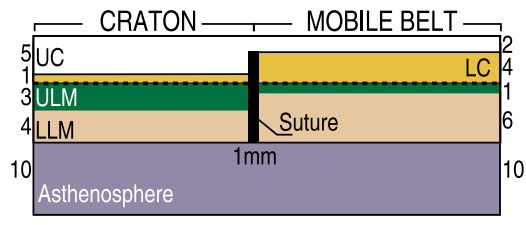

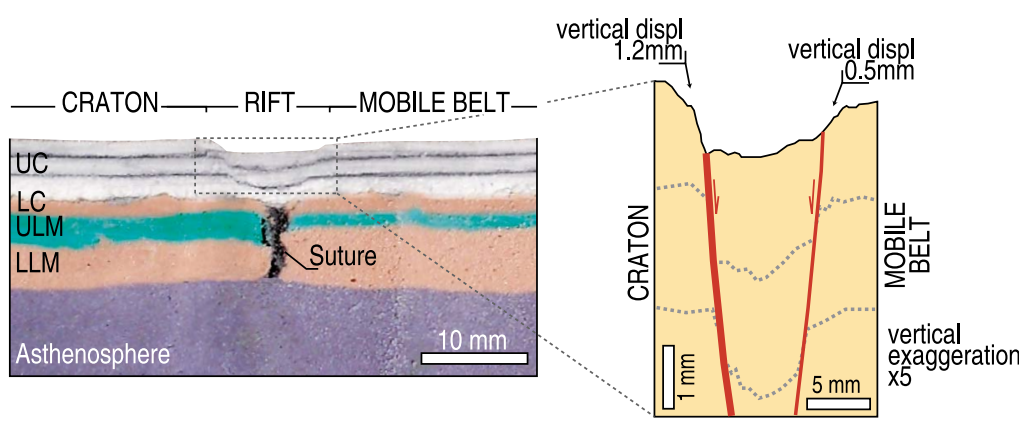

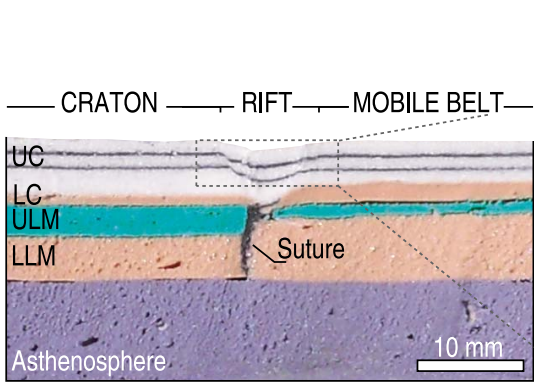

vertical displ
$1.0 \mathrm{~mm}$
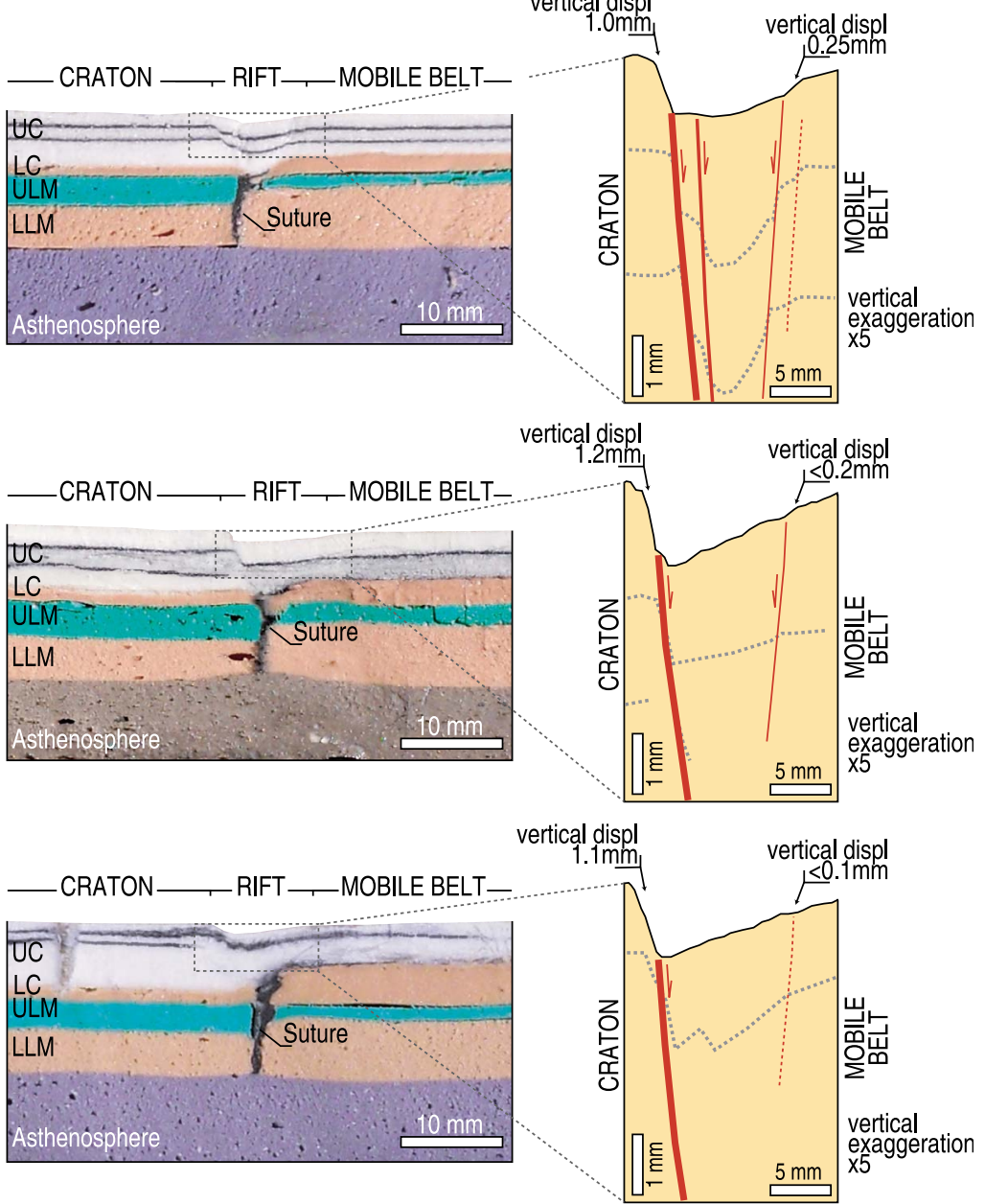

Figure 6. Comparison of different models with suture and variable depth of the brittle-ductile crust transition in the craton and the mobile belt. Note the strong increase in rift asymmetry increasing the variation in brittle-ductile transition depth. Also note that when the craton-belt step in brittle-ductile transition depth is equal to or exceeds $\sim 2 \mathrm{~mm}$, a single major fault on the craton side accommodates extensional deformation, whereas antithetic faults on the mobile belt side are negligible.

suture) the major boundary faults at the craton side accommodated about $65-70 \%$ of total slip; motion on the antithetic faults accounted for the remaining $30-35 \%$ of the vertical displacement (Figure 7a). An increase in the difference of the brittle/ductile ratio at the sides of the suture induced an increase in the amount of slip accommodated at the craton side, and, consequently, in rift asymmetry. When the difference in the brittle-ductile transition depth was equal to or exceeded $\sim 2 \mathrm{~mm}$, a single major fault on the craton side accommodated extensional deformation, whereas antithetic faults on the mobile belt side were negligible (Figures 6 and 7a). The width of the rift was not significantly influenced by this parameter, with only a minor increase increasing the difference in the brittle-ductile transition depth at the sides of the suture (Figure 7b).

[23] Rift asymmetry and basin width were together strongly controlled by the dip of the preexisting weak suture (subseries 1c). Figure 8 shows a comparison between the reference model and model Baikal 32, which was characterized by a similar rheological configuration and an 

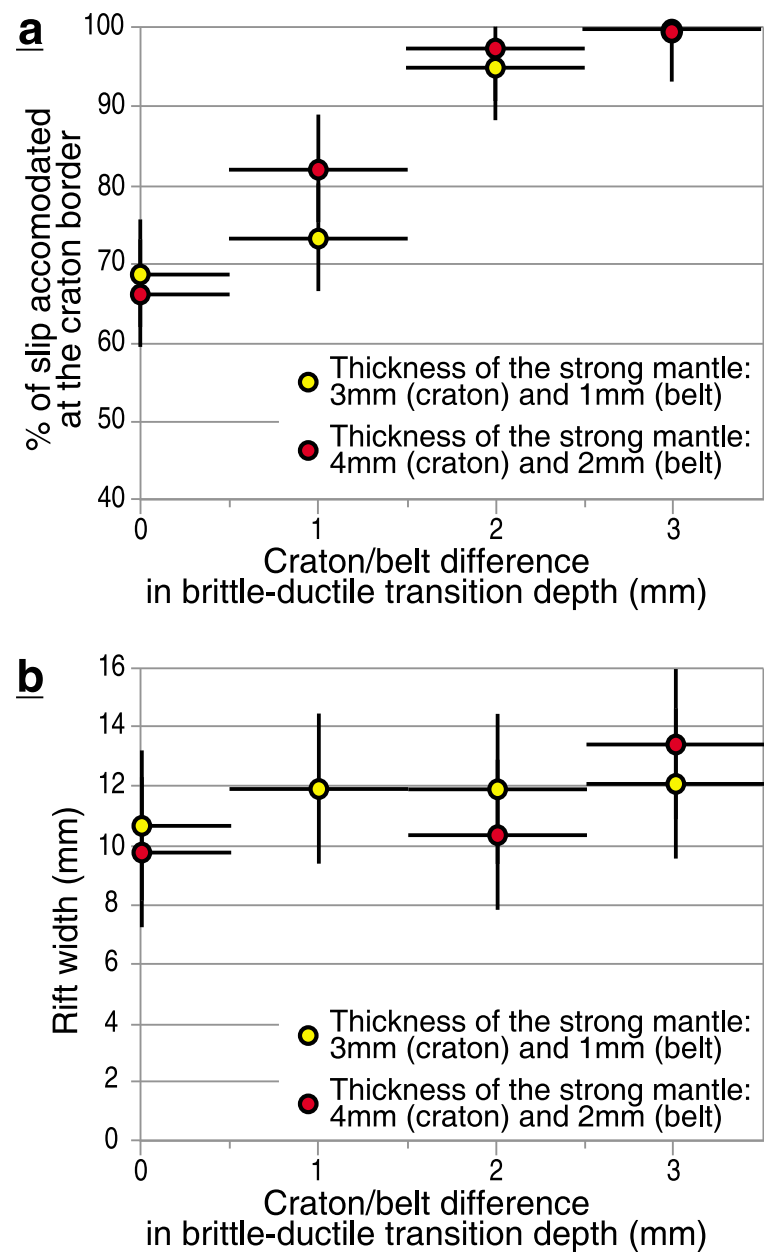

Figure 7. Graphs summarizing the results of subseries $1 \mathrm{~b}$ experiments illustrated as dependence on the difference in brittle/ductile transition depth between the craton and the belt of (a) percentage of slip accommodated at the craton border (calculated by diving the amount of slip at the major boundary faults at the craton side with the total amount of slip at both rift margins) and (b) average rift width.

inclined (not vertical) suture. This comparison shows that, for a similar amount of bulk extension, an inclined suture resulted in a prominent rift asymmetry, with displacement confined to the major fault on the craton side and negligible deformation on the opposite, antithetic faults. Suture inclination also resulted in wider rift depression (rift width was about twice the value measured for the vertical suture; Figure 8) and more prominent asthenospheric upwelling beneath the rift.

[24] Rift characteristics were not significantly influenced by the thickness of the strong lithospheric mantle (subseries 1d), as models with craton-belt thicknesses of 3-1 mm and 4-2 $\mathrm{mm}$ did not show significant differences in terms of rift asymmetry and width (Figure 7). Conversely, the thickness of the brittle crust (subseries 1e) and the width of the weak suture (subseries 1f) controlled rift width (Figures S2 and S3): an increase in both parameters resulted in an wider rift depression, as observed in previous experimental works [Allemand and Brun, 1991; Corti, 2004]. Similarly, the syntectonic accumulation of sediments during progressive subsidence of the rift zone (subseries $1 \mathrm{~g}$ ) influenced rift width, by favoring localization of deformation and the development of narrower depressions (Figures S3 and S4). All these parameters (brittle thickness, suture width, synrift sedimentation) did not affect rift asymmetry significantly. Similarly to the thickness of the strong lithospheric mantle, variations in the thickness of the lower lithospheric mantle (subseries 1h), in turn inducing variations in the depth of the base of the lithosphere at the sides of the suture, did not affect rift characteristics significantly (Figure S5). Experiments with a thin lowermost lithospheric layer in the mobile belt did not show significant differences in terms of rift asymmetry and width with respect to similar models with uniform depth of the base of the lithosphere (Figure S5).

\subsection{Results: Kinematics}

[25] Figure 9 compares the reference model with two other different models in order to illustrate the influence of the variable extension direction on rift architecture. The models had similar rheology, with uniform depth of the brittle-ductile transition at the sides of the suture; as observed in section 4.1, in all the models extension resulted in a striking rift asymmetry, with a major boundary fault system invariably located on the craton side and minor antithetic faults on the belt side. However, the fault pattern and the characteristics of basin subsidence varied according to the different direction of extension.

[26] An E-W extension direction resulted in a rightstepping fault arrangement throughout the model, which testifies a general left-lateral component of motion, well expressed in the model North Baikal and resulting from the relative orientation of the craton border and the direction of extension; long, linear faults were almost absent. In this model, the basin depocenter was located in the model North Baikal and the rift depression became wider proceeding from the South Baikal northward.

[27] A N $115^{\circ} \mathrm{E}$ trending extension resulted in a fault pattern characterized by long, linear faults in the model North Baikal, which testify an almost pure extension, and shorter en echelon faults in the Centre-South Baikal resulting from a minor left-lateral transcurrent component. The basin depocenter was in this experiment located in correspondence to the transition region between the Centre and North Baikal; rift width did not change significantly along strike.

[28] As stated above, the reference model (with a roughly $\mathrm{N} 140^{\circ} \mathrm{E}$ directed extension) was characterized by long, linear major faults in the model Centre-South Baikal, whereas the model North Baikal was affected by en echelon, left-stepping shorter faults testifying a right-lateral component of motion. The basin depocenter was in this model located in the southwestern part of the model Lake Baikal; rift width decreased proceeding northward from the SouthCentre Baikal.

\section{Discussion and Comparison With Nature}

5.1. Model-to-Nature Comparison: Control of Lithospheric Structure and Plate Kinematics on the Architecture and Evolution of the Baikal Rift

[29] Among continental narrow rifts, the Baikal rift is characterized by a narrow deformation zone in which the 
Baikal 14

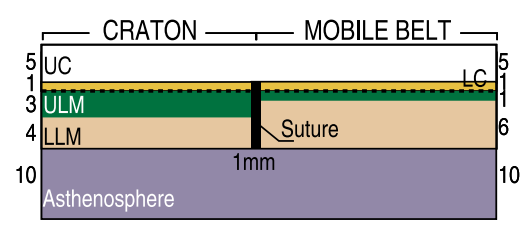

\section{Baikal 32}

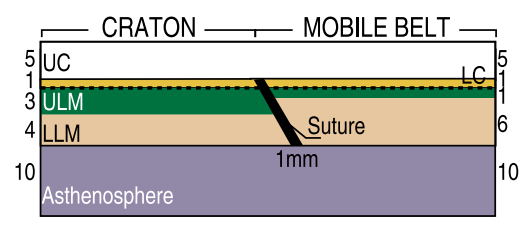

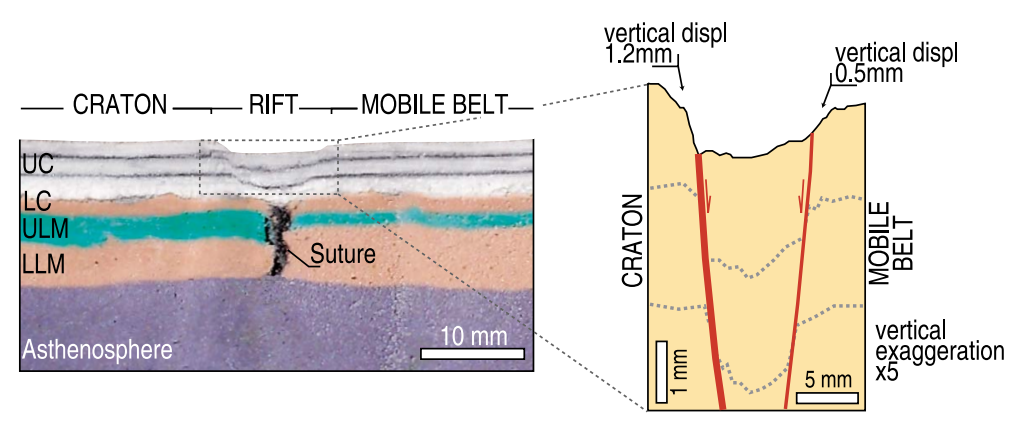

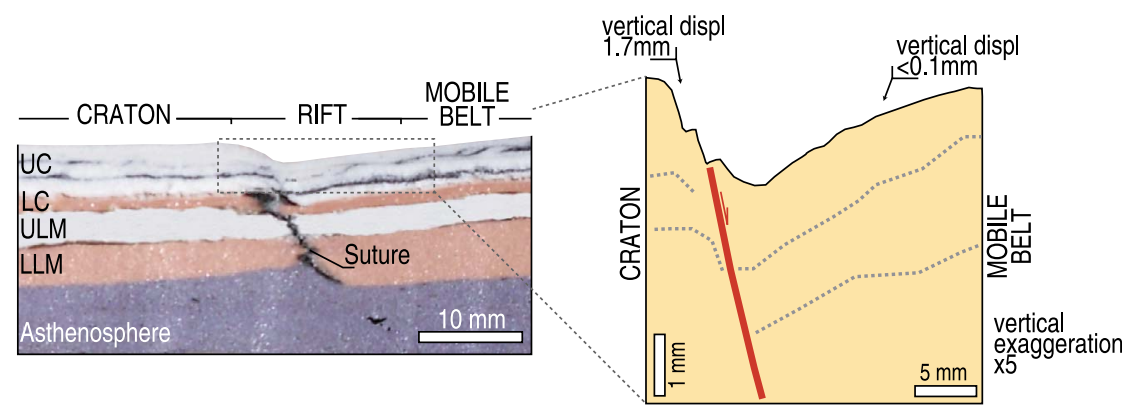

Figure 8. Comparison of models with (top) vertical and (bottom) inclined preexisting suture. Note that for a similar rheological layering, an inclined suture results in substantially higher rift asymmetry and wider depression.

limited amount of extension (likely $<20 \mathrm{~km}$ ) gave rise to strong vertical movements in turn controlling the development of a deep depression hosting up to $8-9 \mathrm{~km}$ of sediments and the deepest lake in the world. Rift localization at the margins of the strong lithosphere of the Siberian craton and the inherited mechanical heterogeneities of the lithosphere likely controlled this anomalous rift structure, as also suggested by previous analog modeling by Chemenda et al. [2002]. Model-to-nature comparison (Figure 10) suggests that the presence of a near-vertical weak suture separating the Siberian cratonic keel from the Sayan-Baikal lithosphere represents the more convenient rheological configuration that leads to a narrow rifting characterized by prominent vertical motions and deep depressions. This result, highlighting the role of the suture as a major weakness zone able to strongly localize deformation, allows us to better explain why this part of the rift currently localizes within a strong lithosphere and not in the weaker adjacent domain [Petit et al., 2008].

[30] In our best fit model, the mobile belt lithosphere is, in agreement with numerical predictions [Petit et al., 2008], characterized by the presence of a thin strong upper lithospheric mantle and reduced thickness of the brittle crust than in the craton. Basin width and asymmetry are optimized for a brittle crust with $30-35 \mathrm{~km}$ thickness in the craton and 10 $15 \mathrm{~km}$ thinner in the belt, fitting the depth distribution of earthquakes [e.g., Déverchère et al., 2001]. With these values, $\sim 20 \mathrm{~km}$ of extension result in a $\sim 50-70 \mathrm{~km}$ wide depression bounded by a single, major boundary fault system on the craton side accommodating $\sim 8-10 \mathrm{~km}$ of asymmetric subsidence of the rift floor, as observed in the natural Baikal. Model results suggest that rift asymmetry is primarily controlled by lateral variations in the rheological layering of the extending lithospheres at the sides of the suture; these variations are still documented across the Baikal rift [see, e.g., Petit et al., 2008].

[31] The model results suggest that an increase in the suture dip leads to a prominent increase in rift asymmetry and width. This latter observation is in agreement with the schematic cross sections of Petit and Déverchère [2006] where the narrow and deep South Baikal basin is located atop a vertical suture whereas the wider Centre Baikal develops above an inclined one. However, these experimental results argue against a control exerted by suture inclination on the along axis, northeastward reduction in rift asymmetry [Petit and Déverchère, 2006]; along-axis variations in crustal structure (e.g., variations in thickness of brittle and ductile layers) at the sides of the suture may likely contribute to the change in rift (a)symmetry proceeding toward the North Baikal.

[32] The analysis of Figure 9 and the model-to-nature comparison illustrated in Figure 10 document that rift architecture is best fitted for a direction of extension oriented similar to the current GPS-derived motion, i.e., $\mathrm{N} 130^{\circ}-140^{\circ} \mathrm{E}$ [see San'kov et al., 2009], and compatible with the stress field of the main (active) rift phase inferred by Delvaux et al. [1997] on the basis of fault and focal mechanism data. With this direction of extension, a striking resemblance of structural pattern between model and nature is observed, specifically concerning (1) the development of major, long, linear faults at the craton side in the CentreSouth Baikal, where the basin depocenters are located; (2) the development of short, left-stepping en echelon faults in the North Baikal, where basin subsidence is less pronounced and the rift depression is narrower; and (3) the overall fault 
(a)

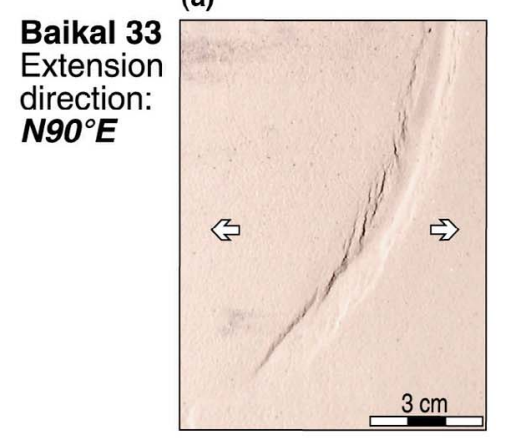

(b)

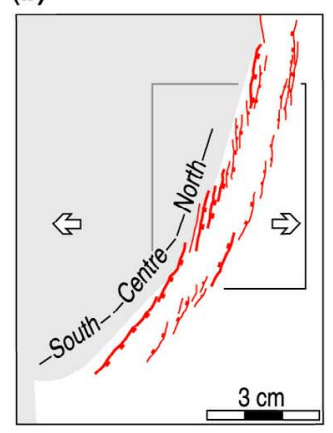

(c)

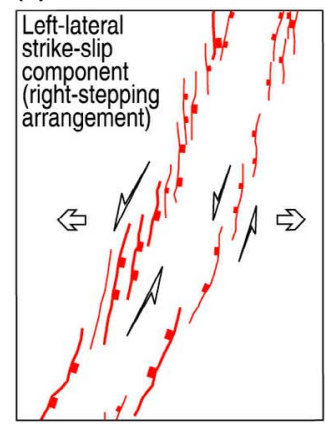

(d)

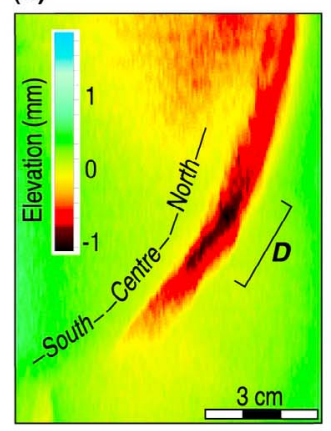

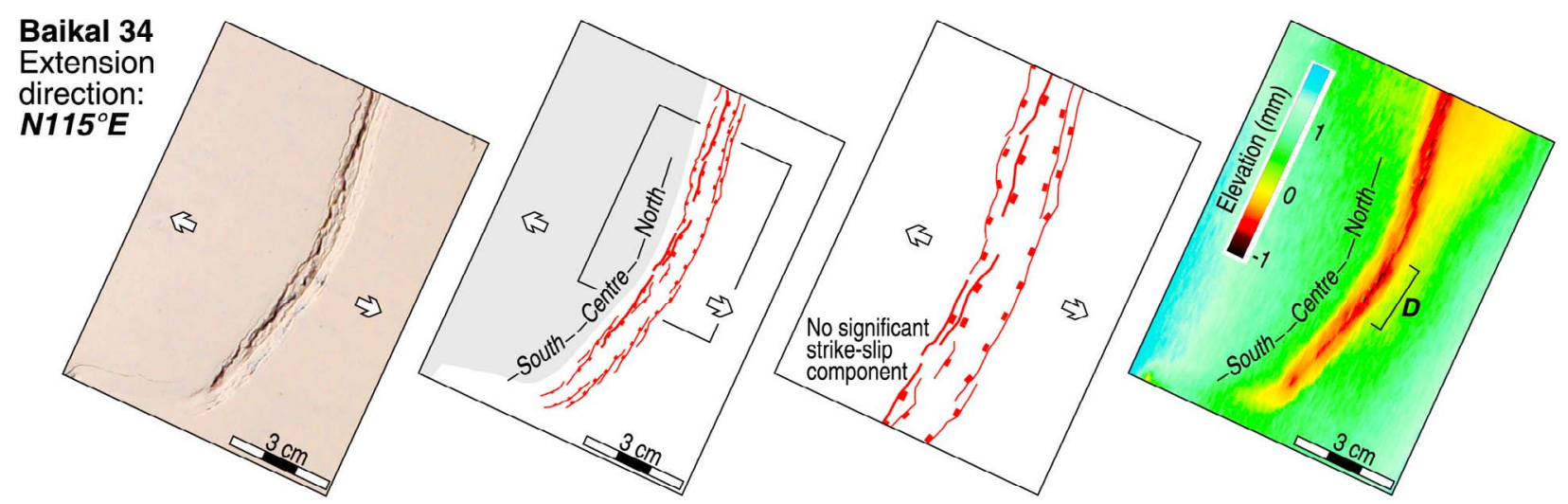

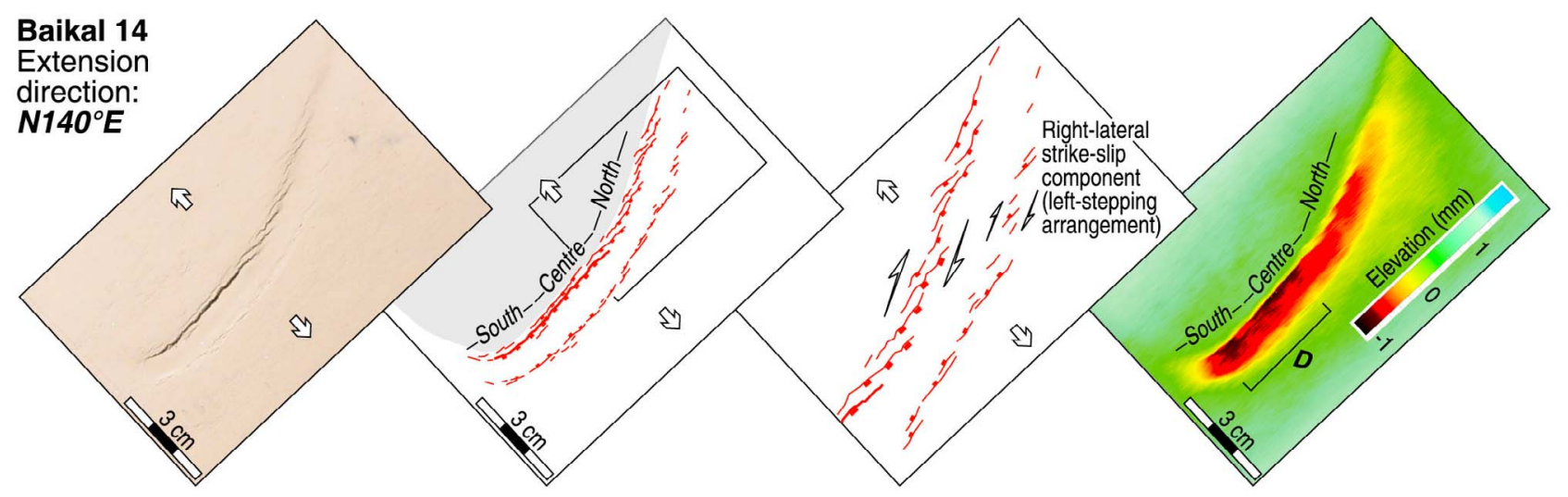

Figure 9. Comparison of models with variable extension direction, illustrated as (a) top-view photo of the model at the end of deformation, (b) line drawing of structures, (c) close-up of line drawing showing fault architecture and characteristics of deformation in the model North Baikal, and (d) digital elevation model of the model surface at the end of deformation with indicated the location of the basin depocenter (D). The models are characterized by a uniform depth of the brittle-ductile transition at the sides of a suture separating the craton and the belt. See text for details.

pattern in terms of distribution of fault orientations (see Figure 10).

[33] The along-axis variation in architecture is related to the relative orientation of the craton border with respect to the $\mathrm{N} 140^{\circ} \mathrm{E}$ directed extension, inducing a transition from pure extension in the Centre-South Baikal to a component of right-lateral shear in the North Baikal. This transcurrent component is responsible for the development of en echelon-arranged faults, for the narrower depression and for the less pronounced basin subsidence, which reflect the oblique extension-related reduction in vertical motion and increase in horizontal component of motion (with associated increase in fault dip [e.g., Tron and Brun, 1991]. Other directions (e.g., E-W, or $\mathrm{N} 115^{\circ} \mathrm{E}$ ) do not fit the natural examples in terms of the fault orientation, architecture and basin depocenter outlined above.

[34] The above analysis suggests that kinematics (in turn controlled by the shape of the Siberian craton) exerted the major control on the fault architecture and its along-axis variations. Preexisting fabrics (other than the large-scale mechanical discontinuity due to the suture) did not play a significant role on the development of the Lake Baikal 
(a)

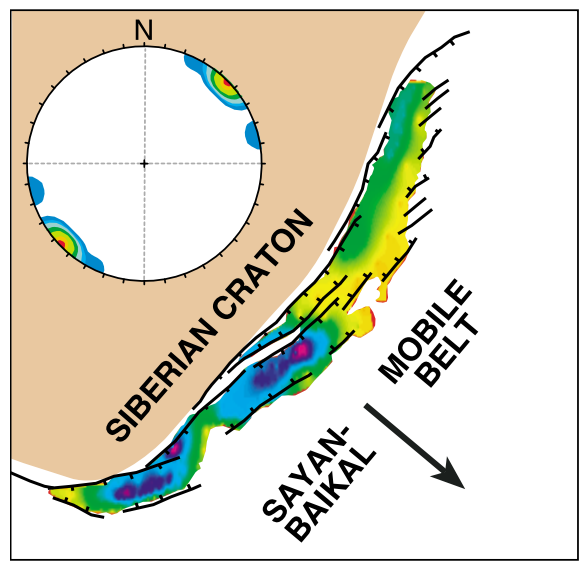

(b)

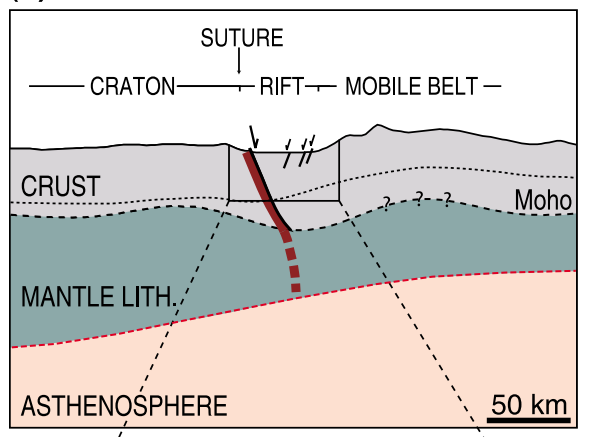

(c)

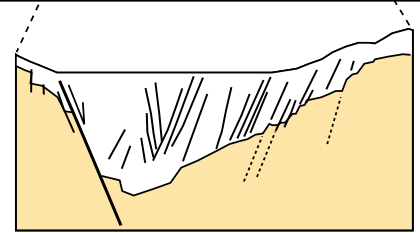

(d)

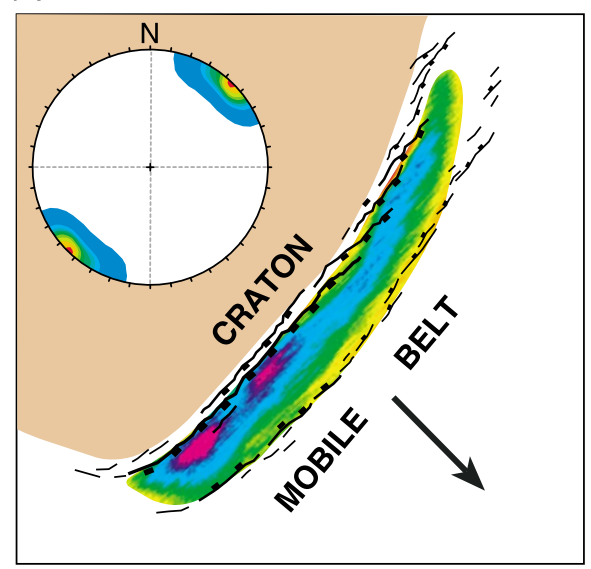

(e)

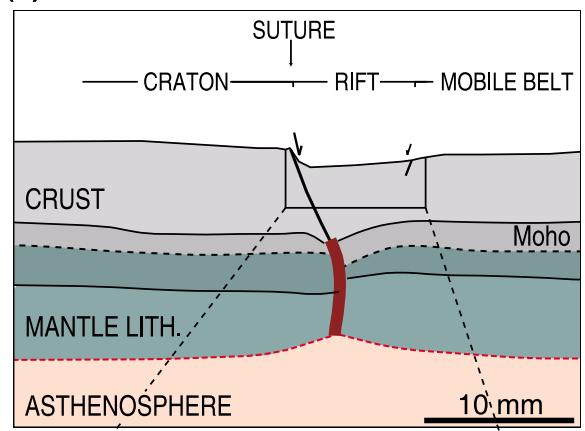

(f)

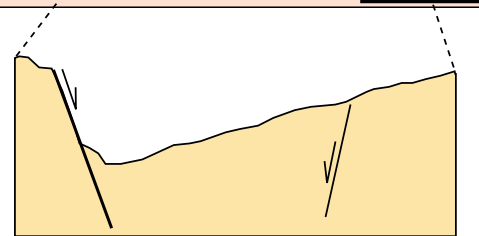

Figure 10. Model-to-nature comparison. (a) Fault pattern and sediment thickness in Lake Baikal [after Petit and Déverchère, 2006], (b) schematic lithospheric-scale cross section [after Petit and Déverchère, 2006], and (c) upper crustal geometry of deformation illustrated as line drawing of a seismic section through the Centre Baikal (see Figure 1 for details). Inset in Figure 10a shows the distribution of faults illustrated as plots of fault azimuths, weighted for the (tip-to-tip) fault length. The weighting factor for each fault is the ratio between the length and the minimum length of the whole data set, such that long faults have higher ratio (weight) than short ones. The frequency of the azimuth of a fault directly relates to this ratio, the longer the fault the higher its frequency. (d-f) Characteristics of deformation of model Baikal 10 illustrated as in Figures 10a-10c. Note the striking similarity between the model and nature in terms of plan view and cross-sectional pattern of extensional structures; the difference in the geometry of the base of the lithosphere likely reflect a prerift thinner lithosphere in the Sayan-Baikal belt.

basins; as an example, the en echelon arrangement of faults in the North Baikal is well reproduced in analog models with no upper crustal fabrics, suggesting that the left-stepping NNE-SSW trending faults result from the strike-slip component of motion, and is not controlled by NE-W trending inherited weaknesses. Moreover, analysis of rift kinematics and its relation to rift architecture suggests that main characteristics of rifting have been acquired during a phase of roughly NW-SE directed extension. This kinematics has been inferred to have characterized the recent (Late Pliocene?) phase of rifting, whereas a roughly E-W directed stretching vector has been suggested for the previous protorift phase of extension [Delvaux et al., 1997]. Extrapolation of model results to nature thus suggests that either (1) rift characteristics were acquired during the recent phase of rifting and the previous protorift phase of extension did not exert a significant control on rift architecture, as it accommodated only a small amount of extension [e.g., Logatchev and Zorin, 1987] and early rift basins were shallower and wider than modern ones [e.g., Kashik and Masilov, 1994], or (2) the direction of extension did not change in time, and a constant NW-SE extension characterized both the recent and the protorift phases.

\subsection{General Implications for Rift Localization, Width, and Asymmetry}

[35] Several previous works have highlighted the occurrence of rift basins along weak areas surrounding strong 
cratonic keels [e.g., Dunbar and Sawyer, 1989; Versfelt and Rosendahl, 1989; Tommasi and Vauchez, 2001; Chemenda et al., 2002; Corti et al., 2003; Ziegler and Cloetingh, 2004; Corti, 2009]; in these conditions, the inherited lithospheric structure and the presence of preexisting weaknesses may represent the primary control on the mode of extension and the width of the resulting continental rifts. Our models suggest that a narrow, weak suture between a strong craton and a mobile belt is able to produce strong strain localization; this results in narrow rift basins in which a limited amount of horizontal plate divergence gives rise to strong vertical motions in turn controlling the development of deep depressions and large vertical throw on boundary faults. We suggest that analogous lateral variations in rheology may have controlled the structure and evolution of Lake Tanganyika in East Africa. There, analogously to the Baikal rift, limited amounts of extension (<20 km [e.g., Morley, 1988]) have led to the development of similar narrow, deep depressions hosting the longest and second deepest lake in the world. As for the case of Lake Baikal, strong strain localization along a weak zone at the western border of the Tanzania craton [e.g., Morley, 2010] likely controlled rift development and architecture.

[36] Continental rifts and passive margins often exhibit a large degree of asymmetry [e.g., Ziegler and Cloetingh, 2004] which changes along strike and, among other controlling parameters, might result from the inherited thermal and mechanical structure of the continental lithosphere at the time of rift inception [e.g., Corti and Manetti, 2006 and references therein]. Our modeling support this observation and suggest that lateral variations in lithospheric rheology may exert the primary control on rift asymmetry. Asymmetry in the models results from both the variation in thickness of the strong mantle between the craton and the belt and, more importantly, from the variation in the depth of the brittle-ductile transition at the sides of the suture. Increasing this variation leads to a prominent increase in rift asymmetry, ultimately leading to extension being accommodated by a single major border fault system on the craton side and a monocline with no significant faulting on the mobile belt side. This is a consistent result of our modeling approach and suggests that the lateral variation in crustal configuration may represent a key factor in controlling rift asymmetry and its along-axis variations. Strong localization of deformation and slip along a single major boundary fault system in asymmetric basins result in deeper sedimentary depocenters with respect to roughly symmetric basins where the more distributed deformation results in less pronounced basin subsidence.

[37] Last, our experimental results support several previous works [e.g., Mart and Dauteuil, 2000; Corti, 2008; Agostini et al., 2009; Autin et al., 2010] in that rift kinematics play a major role in controlling the deformation pattern resulting from extension of the continental lithosphere. The current models and the Baikal example highlights that significant along-axis variations in rift structure may be related to a variable rift kinematics in turn controlled by variations in the plan view geometry of craton keels and suture zones, as for instance previously suggested for the Main Ethiopian rift [Agostini et al., 2011] or the western branch of the East African rift system [Corti et al., 2007].

\section{Conclusions}

[38] The current brittle-ductile analog models investigated the development of the narrow, deep and asymmetric basins hosting Lake Baikal at the margins of the strong Siberian craton. The models suggest the following main conclusions:

[39] 1. A weak narrow suture separating the craton from the weaker Sayan-Baikal mobile belt is required to strongly localize deformation and to lead to the development of a narrow rift characterized by prominent vertical motions and deep depressions; model-to-nature best fit is obtained for a near vertical suture, since an increase in the suture dip leads to basin architectures not compatible with the natural observations.

[40] 2. The typical rift asymmetry is likely controlled by lateral variations in lithospheric rheology, in turn related to both the variation in thickness of the strong mantle between the craton and the belt and, more importantly, from the variation in the brittle-ductile thickness ratio at the sides of the suture. A significant shallowing of the brittle-ductile transition in the crust passing from the craton to the mobile belt is required to fit the asymmetric architecture of the Baikal basins, with a major master fault on the craton side and a monocline with no significant faulting on the mobile belt side.

[41] 3. The overall rift architecture (in terms of plan view fault pattern and basin depocenter location) is best fitted for a $\mathrm{N} 140^{\circ} \mathrm{E}$ directed extension, similar to the current GPSderived motion and compatible with the stress field of the main (active) rift phase inferred on the basis of fault and focal mechanism data; this suggests that either (1) the main characteristics of rifting may have been acquired during the recent (Late Pliocene?) phase of rifting after a first phase of E-W directed extension that did not exert a significant control on rift architecture or (2) the direction of extension did not change in time.

[42] 4. Rift kinematics (in turn controlled by the shape of the Siberian craton) exerted the major control on the plan view fault architecture and its along-axis variations; preexisting fabrics (other than the large-scale mechanical discontinuity due to the suture) did not play a significant role on the development of the Lake Baikal basins.

[43] As more general conclusions, the models support the role of both the prerift lateral variations in rheology between a strong craton and a weaker mobile belt and rift kinematics (and its along-axis variations, in turn dictated by the shape of the craton margins) in controlling rift architecture.

[44] Acknowledgments. We thank Nicolas Bellahsen, Chris Morley, and the Associate Editor for the constructive comments that helped to improve the manuscript. We also warmly thank Vladimir San'kov for proving the reprint of his 2009 paper.

\section{References}

Agostini, A., G. Corti, A. Zeoli, and G. Mulugeta (2009), Evolution, pattern and partitioning of deformation during oblique continental rifting: Inferences from lithospheric-scale centrifuge models, Geochem. Geophys. Geosyst., 10, Q11015, doi:10.1029/2009GC002676. 
Agostini, A., M. Bonini, G. Corti, F. Sani, and F. Mazzarini (2011), Fault architecture in the Main Ethiopian rift and comparison with experimental models: Implications for rift evolution and Nubia-Somalia kinematics, Earth Planet. Sci. Lett., 301, 479-492, doi:10.1016/j.eps1.2010.11.024.

Allemand, P., and J.-P. Brun (1991), Width of continental rifts and rheological layering of the lithosphere, Tectonophysics, 188, 63-69, doi:10.1016/ 0040-1951(91)9034-I.

Autin, J., N. Bellahsen, L. Husson, M. O. Beslier, S. Leroy, and E. d'Acremont (2010), Analogue models of oblique rifting in a cold lithosphere, Tectonics, 29, TC6016, doi:10.1029/2010TC002671.

Buck, W. R. (1991), Modes of continental lithospheric extension, J. Geophys. Res., 96, 20,161-20,178, doi:10.1029/91JB01485.

Calais, E., M. Vergnolle, V. San'kov, A. Lukhnev, A. Miroshnitchenko, S. Amarjargal, and J. Déverchère (2003), GPS measurements of crustal deformation in the Baikal-Mongolia area (1994-2002), Implications for current kinematics of Asia, J. Geophys. Res., 108(B10), 2501, doi:10.1029/2002JB002373

Chemenda, A., J. Déverchère, and E. Calais (2002), Three-dimensional laboratory modeling of rifting: Application to the Baikal rift, Russia, Tectonophysics, 356, 253-273, doi:10.1016/S0040-1951(02)00389-X.

Corti, G. (2004), Centrifuge modelling of the influence of crustal fabrics on the development of transfer zones: Insights into the mechanics of continental rifting architecture, Tectonophysics, 384, 191-208, doi:10.1016/j. tecto.2004.03.014

Corti, G. (2008), Control of rift obliquity on the evolution and segmentation of the Main Ethiopian rift, Nat. Geosci., 1, 258-262, doi:10.1038/ ngeo160.

Corti, G. (2009), Continental rift evolution: From rift initiation to incipient break-up in the Main Ethiopian rift, East Africa, Earth Sci. Rev., 96, 1-53, doi:10.1016/j.earscirev.2009.06.005.

Corti, G., and P. Manetti (2006), Asymmetric rifts due to asymmetric Mohos: An experimental approach, Earth Planet. Sci. Lett., 245, 315-329, doi:10.1016/j.eps1.2006.02.004

Corti, G., M. Bonini, S. Conticelli, F. Innocenti, P. Manetti, and D. Sokoutis (2003), Analogue modeling of continental extension: A review focused on the relations between the patterns of deformation and the presence of magma, Earth Sci. Rev., 63, 169-247, doi:10.1016/S0012-8252(03) 00035-7.

Corti, G., M. Bonini, D. Sokoutis, F. Innocenti, P. Manetti, S. Cloetingh, and G. Mulugeta (2004), Continental rift architecture and patterns of magma migration: A dynamic analysis based on centrifuge models, Tectonics, 23, TC2012, doi:10.1029/2003TC001561.

Corti, G., J. van Wijk, S. Cloetingh, and C. K. Morley (2007), Tectonic inheritance and continental rift architecture: Numerical and analogue models of the East African rift system, Tectonics, 26, TC6006, doi:10.1029/2006TC002086.

de Boisgrollier, T., C. Petit, M. Fournier, P. Leturmy, J.-C. Ringenbach, V. San'kov, S. Anisimova, and S. Kovalenko (2009), Palaeozoic orogeneses around the Siberian craton: Structure and evolution of the Patom belt and foredeep, Tectonics, 28, TC1005, doi:10.1029/2007TC002210.

Delvaux, D., A. Melnikov, and V. D. Ermikov (1995), Paleostress reconstruction and geodynamics of the Baikal region, central Asia, part I, Paleozoic and Mesozoic pre-rift evolution, Tectonophysics, 252, 61-101, doi:10.1016/0040-1951(95)00090-9.

Delvaux, D., R. Moeys, G. Stapel, C. Petit, K. Levi, A. Miroshnichenko, V. Ruzhich, and V. A. San'kov (1997), Paleostress reconstruction and geodynamics of the Baikal region, central Asia, part II, Cenozoic rifting, Tectonophysics, 282, 1-38, doi:10.1016/S0040-1951(97)00210-2.

Déverchère, J., C. Petit, N. Gileva, N. Radziminovitch, V. Melnikova, and V. San'kov (2001), Depth distribution of earthquakes in the Baikal rift system and its implications for the rheology of the lithosphere, Geophys. J. Int., 146, 714-730, doi:10.1046/j.0956-540x.2001.1484.484.x.

Dunbar, J. A., and D. S. Sawyer (1989), Continental rifting at pre-existing lithospheric weaknesses, Nature, 242, 565-571.

Ebinger, C. J., J. A. Jackson, A. N. Foster, and N. J. Hayward (1999), Extensional basin geometry and the elastic lithosphere, Philos. Trans. R. Soc. London A, 357, 741-762.

Hutchinson, D. R., A. J. Golmshtok, L. P. Zonenshain, T. C. Moore, C. A. Scholtz, and K. D. Klitgord (1992), Depositional and tectonic framework of the rift basins of Lake Baikal from multichannel seismic data, Geology, 20, 589-592, doi:10.1130/0091-7613(1992)020<0589:DATFOT $>2.3$ $\mathrm{CO} ; 2$.
Kashik, S. A., and V. N. Masilov (1994), Main stages and palaeogeography of Cenozoic sedimentation in the Baikal rift system (eastern Siberia), Bull. Cent. Rech. Explor. Prod. Elf-Aquitaine, 18, 453-461.

Logatchev, N. A., and N. A. Florensov (1978), The Baikal system of rift valleys, Tectonophysics, 45, 1-13, doi:10.1016/0040-1951(78)90218-4.

Logatchev, N. A., and Y. A. Zorin (1987), Evidence and causes for the twostage development of the Baikal rift, Tectonophysics, 143, 225-234, doi:10.1016/0040-1951(87)90092-8.

Logatchev, N. A., and Y. A. Zorin (1992), Baikal rift zone: Structure and geodynamics, Tectonophysics, 208, 273-286, doi:10.1016/0040-1951 (92)90349-B.

Mart, Y., and O. Dauteuil (2000), Analogue experiments of propagation of oblique rifts, Tectonophysics, 316, 121-132, doi:10.1016/S0040-1951 (99)00231-0.

Melnikov, A. I., A. M. Mazukabzov, E. V. Sklyarov, and E. P. Vasiliev (1994), Baikal rift basement: Structure and tectonic evolution, Bull. Cent. Rech. Explor. Prod. Elf-Aquitaine, 18, 99-122.

Morley, C. K. (1988), Variable extension in Lake Tanganyika, Tectonics, 7 , 785-801, doi:10.1029/TC007i004p00785.

Morley, C. K. (2010), Stress re-orientation along zones of weak fabrics in rifts: An explanation for pure extension in 'oblique' rift segments?, Earth Planet. Sci. Lett., 297, 667-673, doi:10.1016/j.eps1.2010.07.022.

Petit, C., and J. Déverchère (2006), Structure and evolution of the Baikal rift: A synthesis, Geochem. Geophys. Geosyst., 7, Q11016, doi:10.1029/ 2006GC001265

Petit, C., and C. Ebinger (2000), Flexure and mechanical behavior of cratonic lithosphere: Gravity models of the East African and Baikal rifts, J. Geophys. Res., 105, 19,151-19,162, doi:10.1029/2000JB900101.

Petit, C., C. Tiberi, and E. Burov (2008), Strength of the lithosphere and strain localisation in the Baikal rift, Earth Planet. Sci. Lett., 269 523-529, doi:10.1016/j.eps1.2008.03.012.

Ramberg, H. (1981), Gravity, Deformation and the Earth's Crust, 452 pp., Academic, London.

San'kov, V., J. Déverchère, Y. Gaudemer, F. Houdry, and A. Filippov (2000), Geometry and rate of faulting in the North Baikal rift, Siberia, Tectonics, 19, 707-722, doi:10.1029/2000TC900012.

San'kov, V. A., A. V. Lukhnev, A. I. Miroshnichenko, S. V. Ashurkov, L. M. Byzov, M. G. Dembelov, E. Calais, and J. Déverchère (2009), Extension in the Baikal rift: Present-day kinematics of passive rifting, Dokl. Earth Sci., 425, 205-209, doi:10.1134/S1028334X09020056.

ten Brink, U. S., and M. H. Taylor (2002), Crustal structure of central Lake Baikal: Insights into intracontinental rifting, J. Geophys. Res., 107(B7), 2132, doi:10.1029/2001JB000300.

Tommasi, A., and A. Vauchez (2001), Continental rifting parallel to ancient collisional belts: An effect of the mechanical anisotropy of the lithospheric mantle, Earth Planet. Sci. Lett., 185, 199-210, doi:10.1016/ S0012-821X(00)00350-2.

Tron, V., and J. P. Brun (1991), Experiments on oblique rifting in brittleductile systems, Tectonophysics, 188, 71-84, doi:10.1016/0040-1951(91) 90315-J.

van der Beek, P. (1997), Flank uplift and topography at the Central Baikal rift (SE Siberia): A test of kinematic models for continental extension, Tectonics, 16, 122-136, doi:10.1029/96TC02686.

Versfelt, J., and B. R. Rosendahl (1989), Relationships between pre-rift structure and rift architecture in Lakes Tanganyika and Malawi: East Africa, Nature, 337, 354-357, doi:10.1038/337354a0

Ziegler, P. A., and S. A. P. L. Cloetingh (2004), Dynamic processes controlling evolution of rifted basins, Earth Sci. Rev., 64, 1-50, doi:10.1016/ S0012-8252(03)00041-2.

Zorin, Y. A. (1999), Geodynamics of the western part of the MongoliaOkhotsk collisional belt, Trans-Baikal region (Russia) and Mongolia, Tectonophysics, 306, 33-56, doi:10.1016/S0040-1951(99)00042-6.

Zorin, Y. A., and L. Cordell (1991), Crustal extension in the Baikal rift zone, Tectonophysics, 198, 117-121, doi:10.1016/0040-1951(91) 90137-H.

E. Calignano and F. Sani, Dipartimento di Scienze della Terra, Università degli Studi di Firenze, Via G. La Pira, 4, I-50121 Florence, Italy.

G. Corti, Consiglio Nazionale delle Ricerche, Istituto di Geoscienze e Georisorse, Unità Operativa Firenze, Via G. La Pira, 4, I-50121 Florence, Italy. (giacomo.corti@unifi.it)

C. Petit, Geoazur, UMR 6526, CNRS-UNS-UPMC-IRD, La Darse, BP 48, F-06235 Villefranche-sur-mer CEDEX, France. 